\title{
NASA/ARMY/BELL XV-15 TILTROTOR LOW-NOISE TERMINAL AREA OPERATIONS FLIGHT RESEARCH PROGRAM
}

\author{
Bryan D. Edwards \\ Principal Engineer, Acoustics \\ Bell Helicopter Textron, Inc., Fort Worth, Texas \\ bedwards2@bellhelicopter.textron.com
}

\author{
William A Decker \\ Aeronautical Engineer \\ Flight Control and Cockpit Integration Branch \\ Army/NASA Rotorcraft Division \\ NASA Ames Research Center, Moffett Field, California \\ bdecker@mail.arc.nasa.gov
}

\author{
David A. Conner \\ Aerospace Engineer, Aeroflightdynamics Directorate (AMRDEC) \\ U.S. Army Aviationa nd Missile Command, \\ Langley Research Center, Hampton, Virginia \\ d.a.conner@larc.nasa.gov
}

Michael A. Marcolini

Head, Advanced Measurement and Diagnostics Branch

NASA Langley Research Center, Hampton, Virginia

m.a.marcolini@ilarc.nasa.gov

\author{
Peter D. Klein \\ Chief, Advanced Systems Development \\ Bell Helicopter Textron Inc., Fort Worth, Texas \\ pklein@bellhelicopter.textron.com
}

\begin{abstract}
To evaluate the noise reduction potential for tiltrotor aircraft, a series of three $\mathrm{XV}-15$ acoustic flight tests were conducted over a five-year period by a NASA/Army/Bell Helicopter team. Lower hemispherical noise characteristics for a wide range of steady-state terminal area type operating conditions were measured during the Phase 1 test and indicated that the takeoff and level flight conditions were not significant contributors to the total noise of tiltrotor operations. Phase 1 results were also used to design low-noise approach profiles that were tested later during the Phase 2 and Phase 3 tests. These latter phases used large area microphone arrays to directly measure ground noise footprints. Approach profiles emphasized noise reduction while maintaining handling qualities sufficient for tiltrotor commercial passenger ride comfort and flight safety under Instrument Flight Rules (IFR) conditions. This paper will discuss the weather, aircraft, tracking, guidance, and acoustic instrumentation systems, as well as the approach profile design philosophy, and the overall test program philosophy. Acoustic results are presented to document the variation in tiltrotor noise due to changes in operating condition, indicating the potential for significant noise reduction using the unique tiltrotor capability of nacelle tilt. Recommendations are made for a final
\end{abstract}

Presented at the Tiltrotor/Runway Independent Aircraft Technology and Applications Specialists' Meeting of the American Helicopter Society, Arlington, Texas, March 20-21, 2001. This paper is declared a work of the U.S. Government and is not subject to copyright protection in the United States.
$X V-15$ test to define the acoustic benefits of the automated approach capability which has recently been added to this testbed aircraft.

\section{INTRODUCTION}

Many U.S. airports are rapidly reaching their saturation point with regard to the number of daily aircraft operations permitted. Commuter aircraft, flying fairly short routes with relatively few passengers, make up a significant portion of the total airport operations at a large number of these airports, thus significantly limiting the total number of passengers that can use those airports each day (Ref. 1). Tiltrotor aircraft, with their unique capability to take off and land vertically while still flying like an airplane during cruise, provide a potential alternate means of transportation that could link major cities, thus alleviating some of the demand on airports. Research on tiltrotor aircraft has been conducted for many years using such vehicles as the $\mathrm{XV}-3$ and the XV-15, among others. More recently, the Navy has begun procurement of the $\mathrm{V}-22$ Osprey to utilize the capabilities of the tiltrotor for military applications. However, noise generated by the large tiltrotor aircraft is a potential barrier issue for civil market penetration. Tiltrotor aeroacoustics, including primary noise sources and the current state of the art, has been extensively documented in the literature (Ref. 2).

There are two primary ways to reduce the noise produced by a tiltrotor aircraft. One means is by designing an inherently quiet rotor system. This requires a significant lead time and involves complex aeroacoustic and structural design tradeoffs. A second approach is to make use of the nacelle tilt 
capability of a tiltrotor, which allows the aircraft to fly a specified flight path at a number of different rotor operating conditions. To address the issue of noise reduction, NASA initiated an effort with the goal of reducing the overall tiltrotor approach noise within a 40 -acre vertiport by $12 \mathrm{~dB}$ relative to current (1995) technology. This effort is a key part of the Short-Haul (Civil Tiltrotor) (SH(CT)) program which is an element of the Aviation Systems Capacity Initiative within NASA. The objectives and overall scope of the $\mathrm{SH}(\mathrm{CT})$ program have been thoroughly documented (Ref. 3). The goal is to obtain half the noise reduction through design and half through operations.

The concept of noise reduction by flight operations is not new in the rotorcraft industry and is the basis for a decades old Helicopter Association International (HAI) program referred to as the "Fly Neighborly Program" (Ref. 4). The idea is to avoid operating in those regions of the vehicle flight operations envelope that produce high noise levels relative to other regions of the flight envelope. To explore this concept in detail, the NASA Langley and Ames Research Centers conducted an acoustic flight test using a UH60 "Blackhawk" helicopter to determine relative noise levels as a function of flight operating condition (Refs. 5,6). With a noise mapping of the Blackhawk flight envelope in hand, a noise abatement approach profile was designed. To fly noise abatement approach profiles with precision, a flight guidance system was developed at the Ames Research Center which was based on a global position by satellite (GPS) system (Ref. 7). A subsequent flight test to assess the noise abatement potential of this approach profile showed no significant differences in the sound exposure level (SEL) at the three FAA noise certification measurement locations when compared to a standard 6-deg decelerating approach (Ref. 8). However, different conclusions might have been reached if a large area noise footprint had been measured. In 1996, large area noise footprints were measured during a noise abatement flight test involving the NASA Langley and Ames Research Centers, the Volpe National Transportation Systems Center (DOT/FAA), Boeing-Mesa, and Sikorsky Aircraft (Ref. 9). During this test, a Boeing MD Explorer and a Sikorsky S-76B flew noise abatement approaches over a 49-microphone array which was deployed over an area measuring 3,000 ft by $8,000 \mathrm{ft}$. Results for the MD Explorer showed that a two-segmented noise abatement approach profile provided an average 3 to 4 SELdB noise reduction relative to the reference approach profile over a ground area termed as the noise sensitive region under the flight path ( 3,000 to $7,000 \mathrm{ft}$ uprange from the landing point) (Ref. 10). The S-76 noise abatement approach profile showed noise reductions of more than 6 SELdB for distances in excess of $5,000 \mathrm{ft}$ uprange of the landing point when compared to a standard FAA noise certification approach (Ref. 11). However, this same approach showed no significant noise reduc- tions at the FAA certification distance of $3,750 \mathrm{ft}$ uprange of the landing point.

Tiltrotor aircraft have the potential for even more significant noise reduction benefits due to the additional operational variable of nacelle tilt angle. To design noise abatement procedures for tiltrotors, a detailed knowledge of the noise directivity characteristics for many different operating conditions is required. The $\mathrm{XV}-15$ has been the predominant tiltrotor acoustic research aircraft for the last 20 years. As a joint NASA/Army/Bell venture, two XV-15 aircraft were built, and much acoustic testing has been accomplished using these vehicles. Lee and Mosher showed significant variation $(10-15 \mathrm{~dB})$ in noise level as a function of nacelle tilt angle in a test of an XV-15 in the NASA Ames $40 \times 80$ foot wind tunnel (Ref. 12). However, detailed directivity changes could not be measured, because only four microphones were used. Conner and Wellman conducted XV-15 flight tests that successfully mapped the aircraft noise directivity during hover for two different rotor blade sets (Ref. 13). Brieger, Maisel, and Gerdes conducted XV-15 flight tests, acquiring acoustic data during level flight, ascent, and descent operating conditions (Ref. 14). Their results showed a significant variation in noise generation with nacelle tilt, but since acoustic data were only acquired at two sideline angles to each side of the aircraft, directivity information was limited. Edwards (Ref. 15) acquired XV-15 acoustics data for a limited test matrix using a large area microphone array to directly measure the noise footprint. More recently, Conner et al. conducted an extensive $\mathrm{XV}-15$ flight test which used a linear microphone array to successfully map the noise directivity for many different ascent, descent, and level flight operating conditions (Ref. 16). The potential for significant tiltrotor noise reductions with variations in approach profile design (nacelle angle/airspeed/altitude schedule) was shown in a $1997 \mathrm{XV}-15$ acoustic flight test which used a large area microphone array to directly measure noise footprints for a large number of candidate low noise profiles (Ref. 17). Compared to a standard 6-deg approach, a noise abatement approach showed a noise reduction of more than 5 SELdB when averaged over all microphones located between 3,000 ft and 8,000 ft uprange of the landing point, and more than 7 SELdB when averaged over all microphones located between 5,000 and $8,000 \mathrm{ft}$ uprange of the landing point.

In the present paper, results are presented from the most recent series of three $\mathrm{XV}-15$ flight tests conducted by a NASA/Army/Bell Helicopter team that addresses tiltrotor noise reduction by flight operations. These tests were conducted in 1995 (Ref. 16), 1997 (Ref. 17), and 1999 at a remote test site located near Waxahachie, TX. The 1995 test, referred to as Phase 1 , focused on all aspects of terminal area operations (takeoff, approach, and level flight conditions), 
while the 1997 (Phase 2) and 1999 (Phase 3) tests focused exclusively on the approach condition, because this was identified as the area of most concern. The overall program approach philosophy as well as the specific objectives for each test are discussed. Results from each test are presented, including effective ground contours for steady state flight conditions and measured ground footprints for realistic takeoffs and approaches. These results document the variation in tiltrotor noise due to changes in operating condition, and indicate the potential for significant noise reduction using the unique tiltrotor capability of nacelle tilt. Also included are discussions of the weather, aircraft, tracking, guidance, and acoustic instrumentation systems, the low noise approach profile design philosophy, and the use of the Rotorcraft Noise Model (RNM) (Ref. 18) as an aid in the design of quiet approach profiles. This paper is an essentially an update to one presented by Dave Conner at an AIAA conference in June 2000 (Ref. 19).

\section{OVERALL PROGRAM DESIGN}

The overall objective of this flight test program was to determine terminal area flight procedures for tilt-rotors that are consistently quiet, safe, and easy to fly. An XV-15 flight test program was developed that included three separate flight tests, allowing time between the tests to thoroughly analyze the data and use the results to plan the following test. The Phase 1 test (Ref. 16) was designed to assess the relative noise levels produced by tiltrotor aircraft for a broad range of steady-state flight conditions by measuring the lower hemispherical noise characteristics using a linear microphone array. Data were acquired for level flyovers, takeoffs, and approaches. Results indicated that level flyover and takeoff noise levels were insignificant compared to approach noise levels. The remainder of the program, therefore, focused exclusively on developing lownoise approaches. Steady-state noise characteristics for the approaches flown during Phase 1 testing were studied and candidate low-noise approach profiles were designed using engineering judgment and the noise prediction program RNM. The candidate low-noise approach profiles, originally designed from a purely acoustic point of view, were modified to blend noise reduction and handling qualities. The modified candidate low-noise approach profiles were then flown in the Phase 2 flight test (Ref. 17) to assess the noise reduction potential. During this test, the noise footprints were directly measured using a large area microphone array. Handling qualities assessments were provided by the pilots after each approach. The most promising approach profiles from Phase 2 testing were then modified to further improve handling qualities, thus providing a refined set of low-noise approach profiles. In addition, an optimizer was linked with the RNM to provide a couple of new candidate low-noise approach profiles that were then modified for improved handling qualities. The refined set of approach profiles, along with the two new approach profiles, were then tested in the Ames Vertical Motion Simulator (VMS) to assess and, if necessary, improve the handling qualities characteristics prior to the Phase 3 flight test.

\section{EXPERIMENTAL SETUP}

\section{XV-15 Tiltrotor Aircraft}

The XV-15 tiltrotor aircraft (Fig. 1 from Ref. 20) was built by Bell Helicopter Textron, Inc. (hereinafter referred to as Bell), as a proof-of-concept aircraft and technology demonstrator whose first flight was in May 1977. The XV-15 has two $25-\mathrm{ft}(7.6-\mathrm{m})$ diameter rotors mounted on pivoting nacelles that are located on the wingtips. Each nacelle houses a main transmission and a Lycoming T-53 turboshaft engine capable of generating 1,800 shaft horsepower $(1.342 \mathrm{~kW})$. The nacelles are tilted into the vertical position ( $90 \mathrm{deg}$ nacelle angle) for vertical takeoffs and landings and rotated to the horizontal ( 0 deg nacelle angle) for cruising flight. Each rotor has three highly-twisted, square-tip stainless steel blades which typically operate at $589 \mathrm{rpm}$ during hover and transitional flight modes, and at $517 \mathrm{rpm}$ in cruise, corresponding to $98 \%$ and $86 \%$ of rotor design speed. The wings have a $6.5 \mathrm{deg}$ forward sweep to provide clearance for rotor flapping. During this test, the nominal vehicle takeoff gross weight was $13,900 \mathrm{lb}(5,897 \mathrm{~kg})$, including about $2,000 \mathrm{lb}$ $(907 \mathrm{~kg})$ of fuel. During the period of data acquisition, fuel burn-off resulted in an approximately $10 \%$ reduction in the vehicle gross weight. The vehicle was operated by Bell under contract to NASA. In addition, Bell furnished research

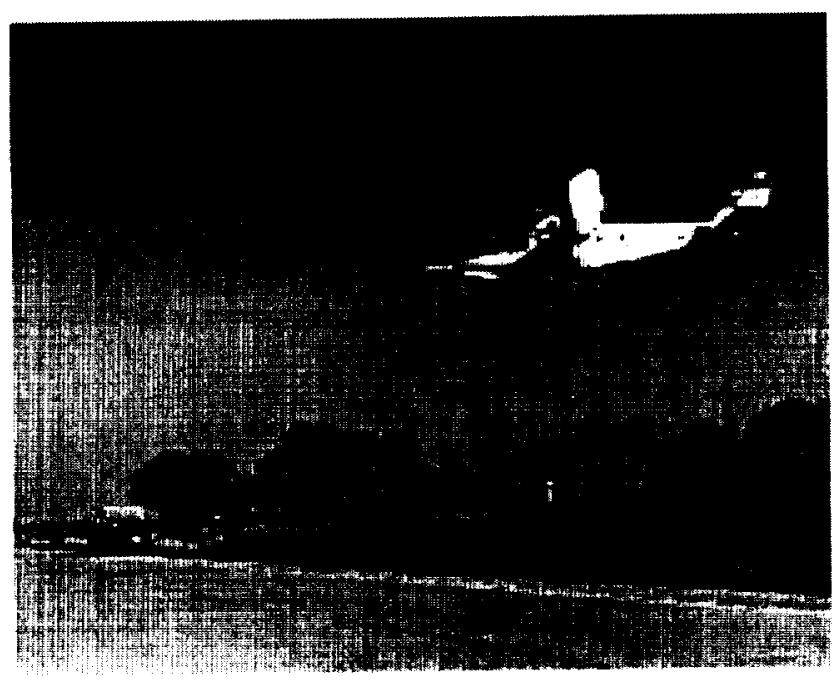

Fig. 1. XV-15 tiltrotor aircraft approaching the landing point at test site near Waxahachie, TX during Phase 3 test. 
pilots, flight test engineers, ground crew personnel, and other necessary support personnel for operation and maintenance of the aircraft and onboard data acquisition system.

The XV-15 featured an impressive suite of onboard instrumentation. Approximately 150 aircraft state parameters were measured and recorded on magnetic tape. Transducers included attitude and rate gyros, strain gauges, temperature sensors, accelerometers, and control position sensors. In addition to the standard onboard instrumentation package, a modified instrument landing system (ILS) was installed for pilot guidance during Phase 1 testing and a differential global positioning system (DGPS) and flight director system (Ref. 21) were installed to provide tracking and pilot guidance during Phase 2 and Phase 3 testing.

The nominal XV-15 flight envelope, shown in Fig. 2, illustrates the combination of nacelle angle and airspeed necessary to achieve stabilized level flight conditions. It should be noted that a fairly broad range of nacelle angles and airspeeds is possible within this operating envelope. The acoustic effects of avoiding certain portions of this range can guide flight operations of the XV-15 (and presumably other tiltrotor aircraft) in minimizing external noise. The flight test series discussed here was designed to define and quantify these effects during terminal area operations.

\section{Aircraft Tracking and Pilot Guidance Systems}

During the Phase 1 test, aircraft tracking was provided by the NASA Ames Precision Automated Tracking System (PATS). The PATS used a pulsed laser beam with a $100 \mathrm{~Hz}$ pulse rate to measure the position of the aircraft within 0.1 mrad in azimuth and elevation and $\pm 1 \mathrm{ft}$ in range. These measurements were then converted to absolute $X, Y$, and $Z$ coordinates with respect to the acoustic reference location. Along with tracking aircraft position, the Ames instrument positioning system (IPS) was used to provide flight path guidance information to the pilots. The IPS compared the actual aircraft position to a pre-selected desired flight

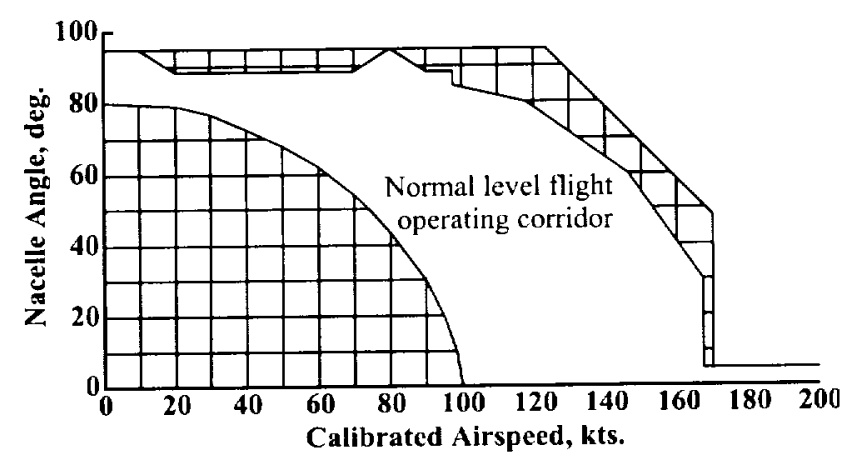

Fig. 2. XV-15 flight envelope. profile, and transmitted an error signal to a traditional ILS receiver and display installed on board the XV-15. This system provided real-time feedback to the pilots regarding their position with respect to the desired flight profile. In addition to the IPS, three 1,000-W metal halide lights with parabolic reflectors oriented towards the aircraft when inbound were deployed along the desired flight path approximately $25 \mathrm{ft}(7.6 \mathrm{~m})$ above ground level at both ends and at the center of the test range property. These lights were visible to the pilots several miles out and provided very useful visual cues of the desired flight path.

During the Phase 2 and 3 tests, aircraft tracking was provided by a 12-channel, dual-frequency Ashtech Model Z-12 GPS receiver installed on board the XV-15. Differential corrections were received from a reference ground GPS unit using a VHF radio modem. The GPS reference ground station consisted of a matching GPS receiver and radio modem. Differential corrections were determined and transmitted to the aircraft twice per second at 19,200 baud. The information from the onboard DGPS receiver was passed from a serial data port to a Bell-designed interface unit. This unit parsed the serial GPS data stream and formatted the values into data words, which were inserted into the aircraft's pulse-code modulated (PCM) data stream. This approach allowed the GPS measurements to be correlated in time with the remainder of the approximately 150 measured aircraft parameters. The PCM data stream, including the GPS parameters, was simultaneously recorded onboard the aircraft and transmitted to the ground telemetry station for real-time monitoring. The three $1,000-\mathrm{W}$ metal halide lights were also deployed during the Phase 2 and Phase 3 tests to provide the pilots with visual ground cues of the desired flight track.

An advanced flight guidance system was used during the 1997 and 1999 flight tests. The XV-15 was fitted with a Silicon Graphics, Inc. computer that calculated the flight director guidance parameters required to perform complex, multi-segmented, decelerating approaches with the required precision (Ref. 21). The flight director computer utilized guidance control laws developed in NASA/Bell simulations specifically for tiltrotor operations (Ref. 22). The computer received DGPS information and other aircraft state parameters by means of an Ethernet communications link with the interface unit. The XV-15 copilot's instrument panel was modified with the installation of a color liquid crystal display (LCD), shown in Fig. 3, which provided essential information for piloting the aircraft, and also provided the information needed for flight director guidance. The flight director provided guidance commands for the desired aircraft configuration, as well as for the desired flight path and velocity profile. Commands were given for the operation of flaps, landing gear, and nacelle conversion angle. Conventional command bars were used for flight path guidance and 
raw data for horizontal and vertical position errors were also provided. Ground speed errors were displayed, and power lever commands were given for airspeed and descent rate control. The nacelle conversion angle and flaps can be used very effectively to reduce pilot workload and control fuselage attitude while flying very precise approach paths.

\section{Meteorological Instrumentation}

Two data systems were used to acquire weather information, a tethered weather balloon system and a weather profiler system. The tethered weather balloon system consisted of an electric winch-controlled, tethered helium-filled balloon; an instrument/telemetry pod; a ground-based receiver/datacontroller; and a ground-based support computer. Profiles of temperature, relative humidity, wind speed, and wind direction were acquired up to $1,000 \mathrm{ft}(305 \mathrm{~m})$ altitude before, during, and after each test flight. An example of the weather data profiles for a typical test period is presented in Fig. 4. The weather profiler system consisted of a $10-\mathrm{m}$ tower with ten temperature sensors, five anemometers, and three wind direction sensors. The weather profiler was used to obtain detailed weather information near the ground. Weather data from both systems were acquired at a rate of at least six points per minute, displayed in real time, and recorded, along with time code, on magnetic disk.

\section{Acoustic Instrumentation}

Several different microphone array configurations and two different data acquisition systems were used to acquire acoustic data during this flight test program. NASA Langley's Digital Acoustic Measurement System (DAMS) was used to deploy a maximum of 30 microphones. With

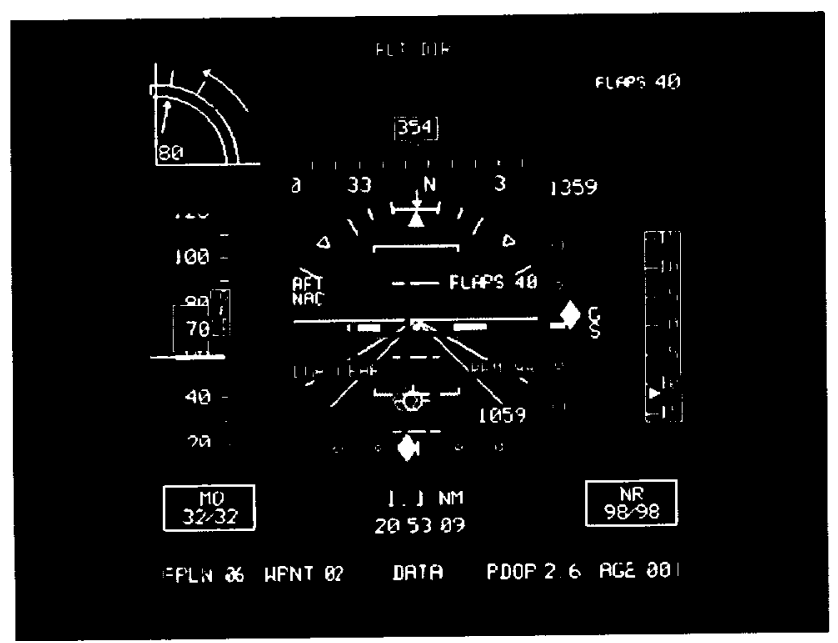

Fig. 3. Flight director cockpit display used during Phase 2 and Phase 3 tests. this system, the microphone signals are digitized at the microphone $(20 \mathrm{kHz}$ sample rate in Phase 1 and Phase 2, 24 $\mathrm{kHz}$ sample rate in Phase 3 ), transmitted via cables to a data van, multiplexed with time and run information, and then recorded on magnetic media (Ref. 25). A maximum of three Langley acoustic data vans were deployed, and each data van handled ten microphone systems. During most of this flight test program, seven additional microphone systems were deployed by Bell, using a Sony PC208Ax eightchannel DAT recorder. The eighth channel was used to record a time code signal. With this system the analog microphone signals were transmitted via cables to the DAT

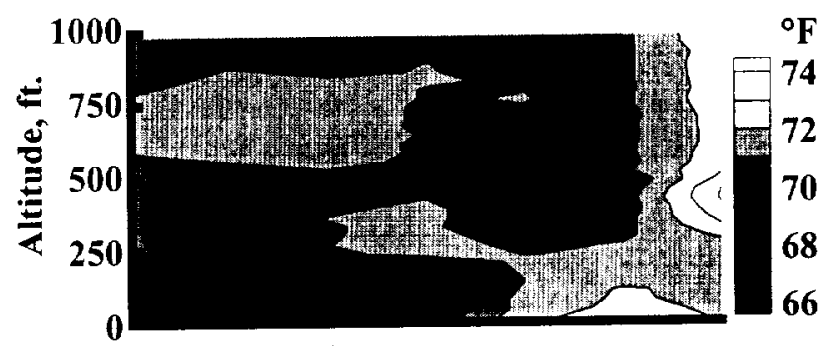

a) temperature

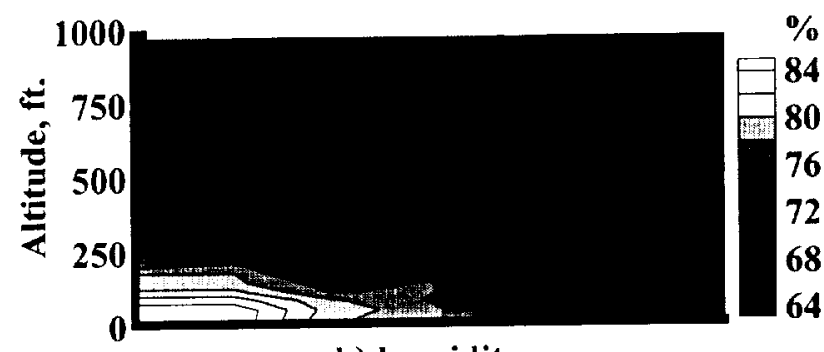

b) humidity

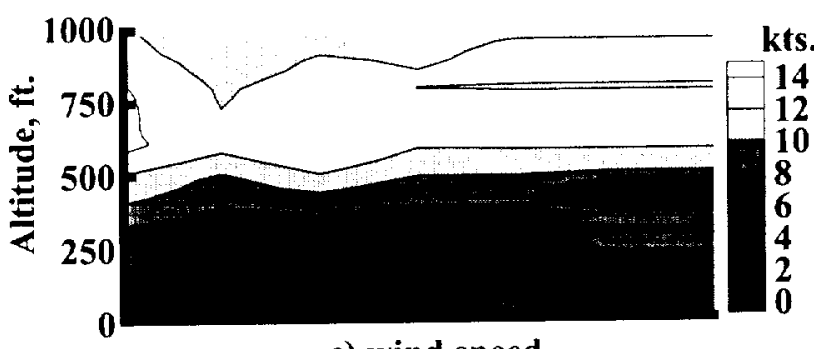

c) wind speed

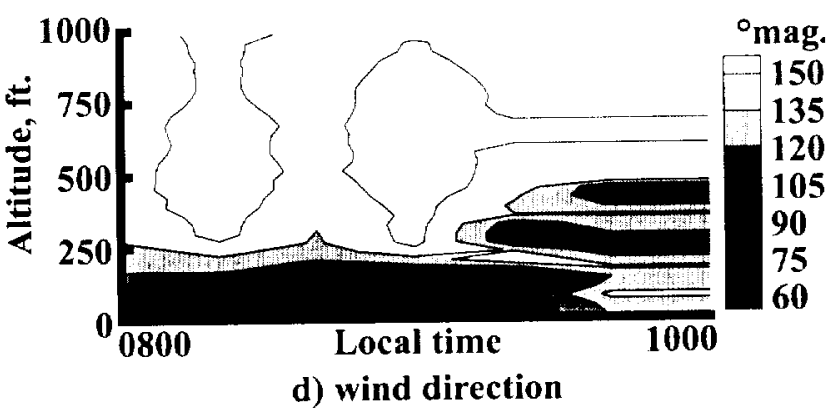

Fig. 4. Weather profiles for a typical test period. 
recorder where they are digitized $(24 \mathrm{kHz}$ sample rate) and recorded on 4-mm tape.

A linear microphone array was primarily used to acquire acoustic data during Phase 1 testing. This array, deployed using Langley's DAMS, consisted of 17 ground board mounted microphones placed along a line perpendicular to the aircraft flight track as shown in Fig. 5. The unequal spacing of the microphones was designed to provide a 10 deg angular resolution to both sidelines when the aircraft passed over the reference microphone at an altitude of $394 \mathrm{ft}$ $(120 \mathrm{~m})$. This microphone array design is useful for measuring the lower hemispherical acoustic characteristics of the test vehicle performing steady state flight operations (constant airspeed, constant glideslope, fixed nacelle angle) (Ref. 6) and to provide data for code validations.

A large area microphone array was deployed to acquire acoustic data during the Phase 2 test. The array consisted of thirty NASA-operated and seven Bell-operated ground board mounted microphones, arranged over a 2,000- $\mathrm{ft}$ by almost 9,000 - $\mathrm{ft}$ area $(600$ by $2,700 \mathrm{~m}$ ) as shown in Fig. 6 . The center of the hover pad, shown as a black-filled circle, was the origin of the coordinate system used during the test $(X=Y=$ $0)$. The desired flight track passed directly overhead of the line of microphones located at $Y=0$, with the aircraft approaching from the $-X$ direction towards the $+X$ direction. The typical run terminated in an IGE hover over the hover pad. Taking advantage of the symmetry of the acoustic radiation pattern about the $\mathrm{XV}-15$ 's longitudinal axis (Ref. 16), the microphone array was designed to measure the noise directly beneath the vehicle and off to the port side only. For the noise data presented in this paper, the representation of noise to the starboard side is the mirror image of the acoustic data measured off the port side of the vehicle. The large area microphone array is useful for measuring actual ground footprints for any type of tiltrotor flight operations,

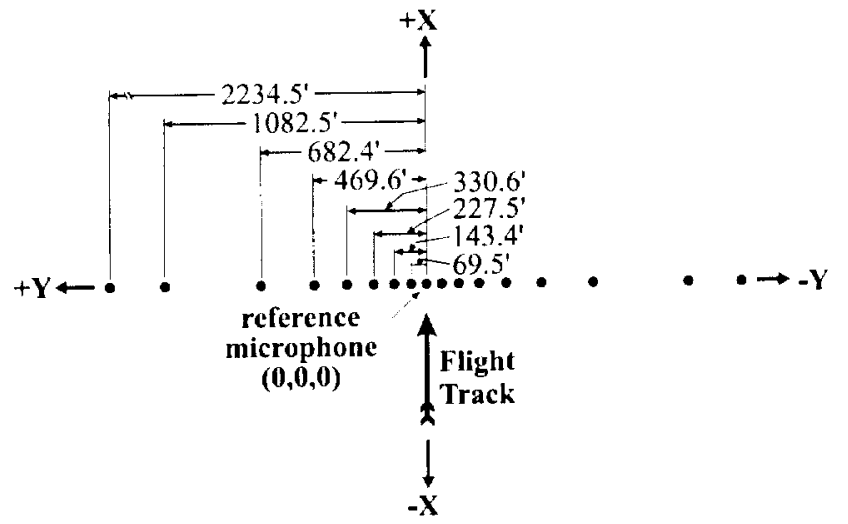

Fig. 5. Linear microphone array used during the Phase 1 test. and is particularly useful for quantification of the acoustic characteristics of a tiltrotor performing highly complex, nonsteady-state approaches. The shape of this array was designed to capture the roughly teardrop shape of the anticipated noise contours for a tiltrotor performing approaches to the hover pad. The array is widest where the noise levels were anticipated to be the greatest, and the width is reduced with increasing distance from the hover pad.

A large area microphone array was again deployed to acquire acoustic data during the Phase 3 test. The array again consisted of thirty NASA-operated and seven Bell-operated ground board mounted microphones, but this time arranged over a 2,000 -ft by 8,000 -ft area $(610$ by $2,400 \mathrm{~m})$ as shown in Fig. 7. During this test it was decided that a more thorough study of the noise reductions provided by the noise abatement approaches at the farther uprange distances would be desirable, since this is the area where the most significant noise differences occur. To accomplish this with the same number of microphones as were available for the Phase 2 test, no microphones were placed near the landing point, as this is the area of least significant noise reductions. Six microphones were located $9,000 \mathrm{ft}(2,700 \mathrm{~m})$ uprange of the landing point, between the centerline and $2,000 \mathrm{ft}(610 \mathrm{~m})$ to the sideline, compared to one centerline microphone located $7,800 \mathrm{ft}(2,397 \mathrm{~m})$ uprange during Phase 2 . In addition, to avoid excessive lost test time due to unfavorable wind directions (as was the case during the Phase 2 test), this array was designed to allow for two different approach headings that were $180 \mathrm{deg}$ apart. The two landing points are shown as large black circles located at coordinates $(0,0)$ and ($10000,0)$. To provide noise footprints of the same dimensions independent of the approach direction, the array was symmetric about a line at $X=-5,000 \mathrm{ft}$. This provided a much greater test window with regards to acceptable wind conditions, defined as predominantly head winds. Testing was terminated if cross winds exceeded $10 \mathrm{kn}$ at any altitude up to $1,000 \mathrm{ft}(304 \mathrm{~m})$. The desired flight track passed directly over the line of microphones located at $Y=0$. Again, taking advantage of the symmetry of the acoustic radiation

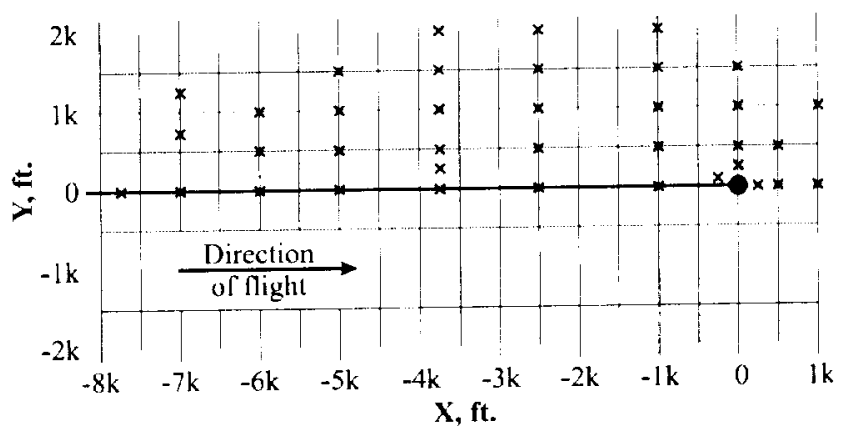

Fig. 6. Large area microphone array used during the Phase 2 test. 
pattern about the XV-15's longitudinal axis (Ref. 16), the microphone array was designed to measure the noise directly beneath and off to one side of the vehicle only. For the noise data presented in this paper, the noise measured to the one side of the aircraft is mirrored to represent the noise on the opposite side of the vehicle.

\section{On-Site Acoustic Data Processing}

At the conclusion of testing each day, the magnetic media containing the digitized acoustic signals from Langley's DAMS were read into DEC Alpha workstations for signal processing. Likewise, 4-mm tapes containing the digitized acoustic signals from the Sony DAT recorder were read into an IBM compatible PC running the LINUX operating system. Start and stop times were selected at the endpoints in time where all data systems (acoustic, aircraft tracking and state, and weather) were simultaneously acquiring data.

During the Phase 1 test, the digital acoustic time domain data were transformed to the frequency domain using 8192 point FFTs with a Hamming window, corresponding to 0.4096 -second blocks of data. The average narrowband spectra were integrated to obtain one-third-octave spectra, which were then integrated to obtain overall sound pressure levels (OASPL). In addition, an A-weighting was applied to each one-third-octave spectrum before integration to provide A-weighted overall sound pressure levels $\left(L_{A}\right)$. By relating the time-dependent OASPL and $L_{A}$ acoustic measurements to the corresponding aircraft position data, effective contours of OASPL and $L_{A}$ were computed using the technique described in Ref. 6. The technique for performing this computation is depicted graphically in Fig. 8. In Fig. 8a, the aircraft flies at a constant operating condition over a linear microphone array that is perpendicular to the flight track. Each data block is related to the aircraft position as shown in Fig. $8 \mathrm{~b}$, which provides noise levels as a function of observer and sideline emission angles. By freezing the aircraft at a point in space, these noise directivity data can be projected onto a ground plane, as shown in Fig. 8c, producing a detailed, high-resolution effective noise contour. While the example

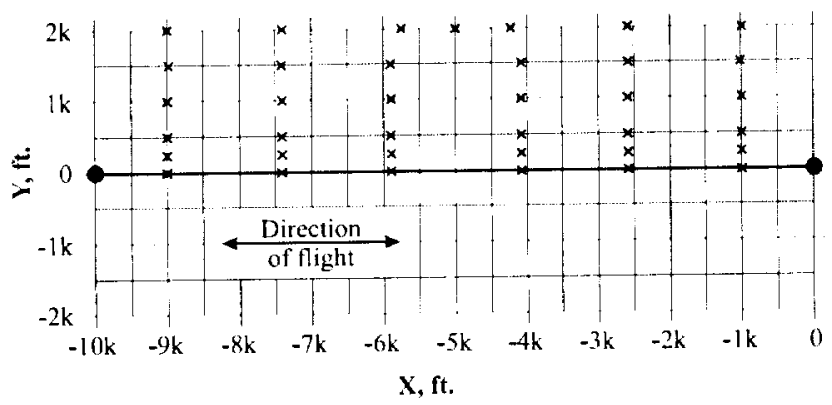

Fig. 7. Large area microphone array used during the Phase 3 test. presents a level flight condition, the same technique can also be used for ascending or descending flight conditions; however, the data as measured project onto a plane that is slanted at the same angle as the flight path. The noise directivity data can also be projected onto a hemisphere, as shown in Fig. 8d, which provides the data in a format required for input to RNM. It should be emphasized that this approach is useful only when the aircraft is operated in a steady-state condition throughout the flyover. In addition to time histories and effective contours, sound exposure levels (SEL) were calculated and plotted as a function of sideline position to help facilitate comparisons of the different test conditions.

During the Phase 2 and Phase 3 tests, the digital acoustic time domain data were transformed to the frequency domain using the average of five 4,096-point FFTs with a Hamming window and $50 \%$ overlap applied. This resulted in $0.6144-$ second blocks of data for the Phase 2 DAMS data and 0.5120 second blocks of data for the Phase 3 DAMS data and the DAT data. These averaged narrowband spectra were computed beginning every 0.5 second for the duration of

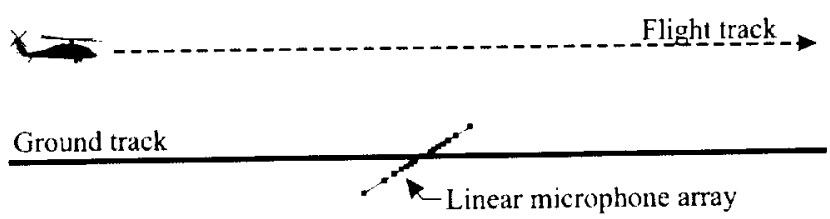

a) Source flyover of a linear microphone array.

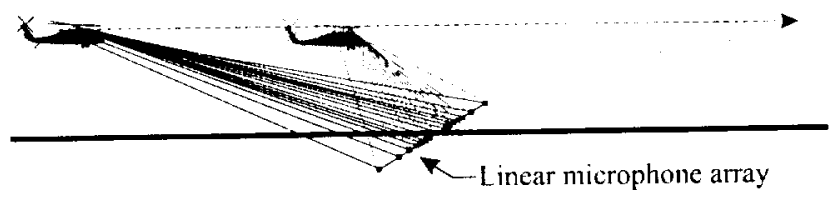

b) Acoustic data measured during flyover.

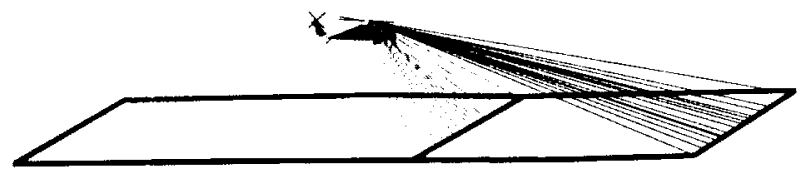

c) Single source transformation to a plane.

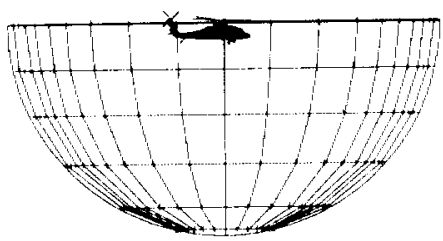

d) Single source transformation to a hemisphere.

Fig. 8. Single source effective surface contour calculation. 
each run. The average narrowband spectra were then integrated to obtain one-third-octave spectra, and for the DAT data only, corrections were applied to account for analog signal line losses. Line loss corrections were not required for the DAMS data since the microphone signals were digitized at the microphone. The corrected one-third-octave band spectra were then integrated to obtain OASPL. In addition, an A-weighting was applied to each one-third-octave spectrum before integration to provide $L_{A}$. These $L_{A}$ results were then integrated over the time period corresponding to the $10 \mathrm{~dB}$ down point from the maximum level for computation of SEL. Data plots were generally available the day following acquisition.

\section{Flight Procedures}

During these tests, real-time communications were established between project control, each acoustic site, and the meteorological test site. Real-time communications were established on a different channel between project control and the XV-15 aircraft. Each time the XV-15 arrived at the test site, a level flight pass was made at $60 \mathrm{deg}$ nacelle angle and $90 \mathrm{kn}$ airspeed, and a target altitude of $394 \mathrm{ft}(120 \mathrm{~m})$ above ground level (AGL). These "housekeeping" passes were conducted to check the day-to-day consistency of the measurements, and as a quick check to verify the proper operation of all systems.

The aircraft flew steady-state level flyover, takeoff, and approach profiles during the Phase 1 test. All profiles were designed in such a manner that the aircraft passed over the reference microphone at an altitude of $394 \mathrm{ft}(120 \mathrm{~m})$. For the level flyover and takeoff profiles, data acquisition began and ended when the aircraft was approximately I mile (1.6 $\mathrm{km})$ from the linear microphone array. For the takeoff profiles, the aircraft approached the microphone array at $100 \mathrm{ft}$ altitude at the velocity for best-rate-of-climb, $V_{y}$, and pulled up into a best-rate-of-climb ascent at an uprange distance that would put the aircraft at about $394 \mathrm{ft}(120 \mathrm{~m})$ altitude when it passed over the microphone array. The run was terminated when the aircraft was about 1 mile $(1.6 \mathrm{~km})$ downrange. For the approach profiles, the aircraft approached in level flight at an altitude that allowed the selected glideslope ( $3 \mathrm{deg}, 6 \mathrm{deg}, 9 \mathrm{deg}$, or $12 \mathrm{deg}$ ) to be intercepted at a point about three miles uprange. Data acquisition began when the aircraft was about 2.5 miles ( $4 \mathrm{~km}$ ) uprange, which allowed sufficient time for the pilot to obtain steadystate conditions on the prescribed glide slope. The approach continued, passing over the microphone array at about $394 \mathrm{ft}$ $(120 \mathrm{~m})$ altitude, until the aircraft was at an altitude of $100 \mathrm{ft}$ $(30 \mathrm{~m})$ or less, at which time the pilot radioed "Prime data off" just prior to pulling the aircraft out of the steady-state descent condition.
During Phase 2 testing, each approach began approximately 5 miles $(8 \mathrm{~km})$ uprange of the microphone array, at an altitude of 1,500 to $2,000 \mathrm{ft}$ ( 460 to $610 \mathrm{~m}$ ) AGL. At approximately 3 miles $(4.8 \mathrm{~km})$ uprange, the desired flight procedure was initiated, and the test director radioed "Prime data on." The XV-15 continued along the flight track, passing over the microphone array and decelerating to an IGE hover over the center of the hover pad. At this point the test director radioed "Prime data off" and data acquisition was discontinued. The XV-15 then climbed out and set up for the next data pass. In addition to the housekeeping pass, approximately six approaches were conducted during a single data flight before refueling of the aircraft was required.

Phase 3 approaches were conducted nearly identically to the Phase 2 approaches, with the exception that they did not terminate with the aircraft in an IGE hover over the hover point. Instead, the pilot held the prescribed approach conditions until the aircraft had flared and slowed to about $20 \mathrm{kn}$ airspeed at an uprange distance of no more than a couple of hundred feet $(60 \mathrm{~m})$ and an altitude of 50 to $100 \mathrm{ft}$ (15 to 30 $m$ ). The pilot then radioed "Prime data off," and immediately performed a climbout to set up for the next data run. It was determined that an IGE hover was not required, since the closest microphone was located 1,000 $\mathrm{ft}$ (304 m) uprange of the landing point. This procedure, which required slightly less flight time, combined with a small increase in the XV15 fuel capacity, permitted seven approaches per flight in addition to the housekeeping pass.

Since information on handling qualities for each of the Phase 2 and Phase 3 approach procedures was desired, the pilot was requested to make comments after each approach. An onboard video recorder had been installed to record the flight director screen during each pass. Pilot comments were recorded on the audio track of this recorder and then transcribed for future reference.

\section{Approach Profile Design Philosophy}

Designing approach profiles that are quiet, safe, easy to fly, and repeatable requires interdisciplinary cooperation between acousticians, handling qualities experts, and pilots. Constraints are imposed by the capabilities of the specific aircraft and its control systems. For this test program, the initial candidate low-noise profiles were developed primarily using acoustic considerations, tempered with some minimal constraints concerning maximum deceleration and descent rates, along with nacelle angle conversion times. Slightly different techniques were used to design the approaches for Phase 2 and Phase 3, however. In both cases, the authors used measured results from the Phase 1 test as input into the RNM. Although it was not yet complete when planning for 
Phase 2 began, RNM still provided a tool to assess the resulting noise produced when combining several different flight procedures into a candidate approach profile. Noise footprints produced by using different combinations of airspeed, nacelle angle, and glideslope were examined and compared with a baseline $6 \mathrm{deg}$ glideslope $/ 70 \mathrm{kn} / 85 \mathrm{deg}$ nacelle angle approach.

In Phase 2, a set of ten initial candidate profiles were developed using a somewhat ad hoc approach based on examination of the Phase 1 results. These initial profiles were then modified to reflect prior simulator experience with tiltrotor instrument approach procedures, as well as attempting to provide acceptable handling qualities. Approach profile design priorities were as follows: first, to maximize the maneuvering portion of the approach over the $8,000 \mathrm{ft}(2,440$ $\mathrm{m}$ ) of microphone array; second, to aim for low noise flight conditions identified in the Phase 1 test; and finally, the resulting profiles were adjusted in an attempt to provide acceptable handling qualities (priority to tracking performance) for the rate-stabilized XV-15. Examples of modifications made to the approach profiles include specifying the time required to change the glideslope (rate of flight path angle change of $0.5 \mathrm{deg} / \mathrm{s}$ ), modeling the natural braking effect produced when the nacelle angle is increased as part of selecting the deceleration rates $(0.063 \mathrm{~g}$ deceleration matched average decelerations with nacelle moves for the $\mathrm{XV}-15$ ), and including a 5 -second buffer after a glideslope change or nacelle movement to provide time for the pilot to stabilize on the new flight condition and to prepare for the next change command. Four additional profiles were developed based on previous flight simulations done in the VMS at NASA Ames. These procedures had acceptable handling qualities, but their noise impact was unknown. All of the profiles discussed here were designed for "zero wind" conditions. During Phase 2 testing, which was limited to a single approach direction, the test site experienced significant prevailing winds that forced the $X V-15$ to operate with a tail wind in excess of $10 \mathrm{kn}$ most days, since the microphone array and the landing pad were fixed on the ground. In an attempt to accommodate these weather conditions, some of the approach profiles were modified with increased commanded (inertial) ground speed.

To design the approach profiles for the Phase 3 test, a similar technique was used as in Phase 2, and the results of that testing were incorporated as well. However, a more systematic procedure was followed this time, based on the experience gained during Phase 2. First, several of the quieter approaches from Phase 2 that also had fairly acceptable handling qualities were included with very little modification. However, in an attempt to identify alternative low noise approach profiles, RNM was coupled with iSIGHT (Ref. 24), a commercially available optimizer. Since it was not practical to optimize based on contour information, the optimization was performed based on the noise predicted by RNM at three microphone locations directly below the flight path, at $2,000,4,000$, and $6,000 \mathrm{ft}(610,1,220$, and $1,830 \mathrm{~m})$ upstream of the landing point. Constraints were used to prevent the optimizer from selecting flight conditions that were outside the XV-15 flight envelope, and to ensure that the approach ended in an aircraft state viable for landing. The optimized approach profiles were then slightly adapted using the lessons learned from the Phase 2 testing to try to produce acceptable handling qualities, and then input to RNM to produce a predicted noise footprint for each candidate approach. All profiles were then tested using a real-time simulation model on a development workstation, while several were also tested in the VMS to refine handling qualities profile design constraints. Smoothed guidance inputs for all candidate Phase 3 profiles were developed on the real-time simulation workstation associated with the VMS. The potential for use of the XV-15's full flap position, rarely used due to its higher hover download, was noted during this development. The $75 \mathrm{deg}$ flap position provided a more desirable body pitch attitude while increasing the rotor-engine power requirement to a more controllable state during steep descents. The profiles were then implemented for the test aircraft guidance system, then checked and evaluated in the $\mathrm{XV}-15$ simulator at Bell. Based on feedback from the pilots, these approach profiles were further modified before the beginning of the Phase 3 testing. Once testing began, all of the approaches were then evaluated in the aircraft itself, and further refinements were made if necessary. Once the approach profiles were finalized, multiple repeats of each one were made over the microphone array. Since the array used in the Phase 3 testing could accommodate two flight directions, $180 \mathrm{deg}$ apart, no adaptation for tailwinds was required during this testing.

\section{RESULTS AND ANALYSIS}

\section{Data Repeatability}

As an example of the repeatability of the data acquired during this test program, sound exposure levels for the most densely populated line of microphones during the Phase 2 test, located $3,750 \mathrm{ft}(1,100 \mathrm{~m})$ uprange, are presented as a function of the sideline distance for all the housekeeping runs and for all the 6 deg approaches in Figs. 9a and 9b, respectively. The figures show that, as one would expect, the maximum sound exposure levels were measured on the flight path centerline and the levels decrease rapidly with increasing sideline distance. For the housekeeping runs of Fig. 9a, the SEL variation for the centerline microphone and all microphones up to $1,000 \mathrm{ft}(304 \mathrm{~m})$ to the sideline are approximately $\pm 0.6 \mathrm{~dB}$ or less. The largest SEL variations are approximately $\pm 1.6 \mathrm{~dB}$ for the microphones located 
1,500 and $2,000 \mathrm{ft}(460$ and $610 \mathrm{~m}$ ) to the sideline. Fig. $9 \mathrm{~b}$ shows that the SEL variations for the $6 \mathrm{deg}$ approaches was approximately $\pm 2.25 \mathrm{~dB}$ or less for all microphones, except the farthest-out microphone located $2,000 \mathrm{ft}(610 \mathrm{~m})$ to the sideline, which had a slightly greater variation of $\pm 2.75 \mathrm{~dB}$. These variations are consistent with what was measured during the Phase 1 and Phase 3 tests.

\section{PHASE 1 RESULTS}

The types of analyses that were used to judge the relative noise levels of all the steady-state approaches flown during Phase 1 testing are presented below. In addition, lower hemispherical noise contours were developed for all Phase 1 approaches and level flyovers, and used as input to RNM. When there were multiple runs of the same flight condition, the data were averaged over those runs to provide a single average noise hemisphere. A total of 76 hemispheres were generated, including $3 \mathrm{deg}, 6 \mathrm{deg}, 9 \mathrm{deg}$, and $12 \mathrm{deg}$ approaches for a range of airspeeds and nacelle angles.

Fig. 10 presents the SEL as a function of the sideline distance for $9 \mathrm{deg} / 70 \mathrm{kn}$ steady-state approaches at nacelle an-

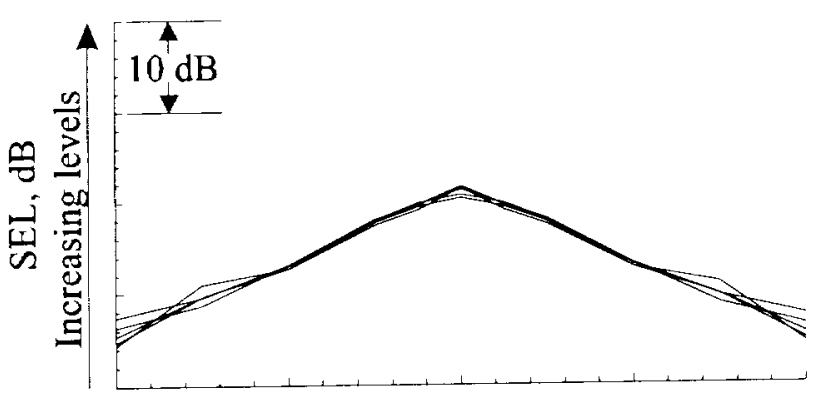

a) "Housekeeping" runs (level flyovers at $60^{\circ}$ nacelle angle, 90 knots.)

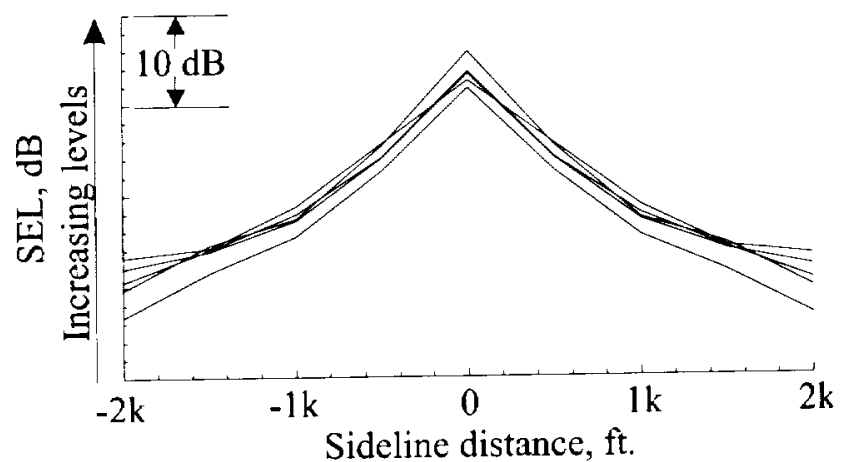

b) $6^{\circ}$ approaches to IGE hover.

Fig. 9. Sound exposure levels for multiple runs at the same flight condition, as measured 3,750 ft uprange of the landing point during the Phase 2 test. gles of $60 \mathrm{deg}, 70 \mathrm{deg}, 80 \mathrm{deg}, 85 \mathrm{deg}$, and $90 \mathrm{deg}$. In general, the SEL increases with increasing nacelle angle. The greatest variation occurs directly under the flight track, where the difference between the minimum and maximum level is $10 \mathrm{~dB}$. The variation decreases with increasing sideline distance and is less than $2 \mathrm{~dB}$ at $2,200 \mathrm{ft}(670 \mathrm{~m})$ to either side of the flight track. The variation in SEL is somewhat greater to the port side of the aircraft (positive sideline direction) than to the starboard side. This is due to differences in the actual flight tracks from the desired flight track of $Y=0$. The flight tracks for the $60 \mathrm{deg}$ and $70 \mathrm{deg}$ nacelle angle approaches were $-49 \mathrm{ft}$ and $-100 \mathrm{ft}(15 \mathrm{~m}$ and $30 \mathrm{~m})$ to the sideline when the aircraft passed over the microphone array, while the other approaches were $-2,7$, and $17 \mathrm{ft}(-0.6$, 2.1 , and $5.2 \mathrm{~m}$ ) to the sideline. Hence, if these differences in track were taken into account, the noise directivity to the port and starboard sides would be more nearly symmetrical.

Fig. 11 presents A-weighted OASPL noise contours for the $60 \mathrm{deg}$ and $90 \mathrm{deg}$ nacelle angle approaches presented in Fig. 10. These contours were developed using the technique described in the discussion of Fig. 8. The contours represent the noise radiated from the $\mathrm{XV}-15$ to a ground plane that is tilted at the 9 deg approach angle and moving with the aircraft, which is located $394 \mathrm{ft}(120 \mathrm{~m})$ above the point marked with a plus $(+)$ at coordinates $(0,0)$. The contours extend over different ranges of $X$ due to differences in the aircraft distance from the microphone array when data acquisition began and ended. The 60 deg nacelle angle approach (Fig. $1 \mathrm{lb}$ ) shows that the area contained within any given contour level has been reduced significantly compared to the 90 deg nacelle angle approach (Fig. 11a), and the

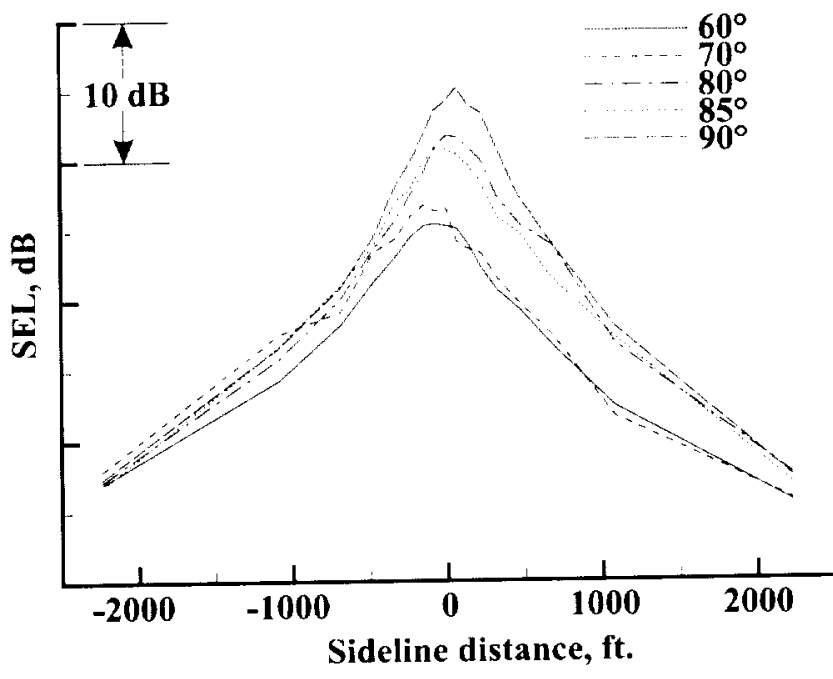

Fig. 10. Variation of SEL with nacelle angle for constant conditions of $70 \mathrm{kn}$ airspeed, 9 deg approach angle as measured during the Phase 1 test. 


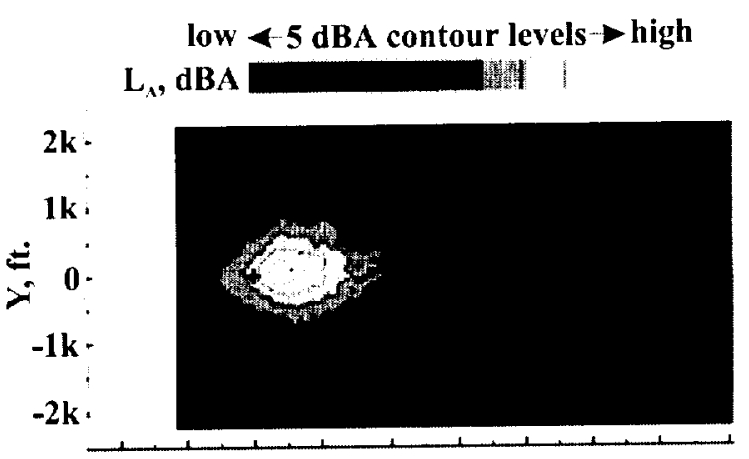

a) $90^{\circ}$ nacelle angle

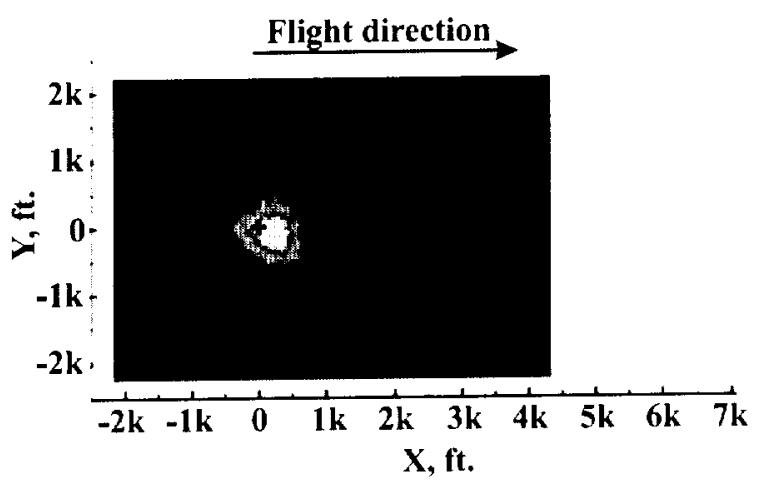

b) $60^{\circ}$ nacelle angle

Fig. 11. $L_{A}$ contours for $70 \mathrm{kn}, 9 \mathrm{deg}$ approaches as measured during the Phase 1 test.

maximum contour level has been reduced by $5 \mathrm{dBA}$. Figs. 10 and 11 illustrate the significant noise abatement potential offered by the unique tiltrotor capability of nacelle tilt during approach operations. However, the amount of noise reduction appears to decrease with increasing sideline distance, as is the case for helicopters using noise abatement procedures (Ref. 25).

\section{PHASE 2 RESULTS}

During the Phase 2 flight test, noise footprints were measured for candidate low-noise approaches. The measured noise footprints extended from $1,000 \mathrm{ft}(304 \mathrm{~m})$ downrange to $8,000 \mathrm{ft}(2,440 \mathrm{~m})$ uprange, and up to $2,000 \mathrm{ft}$ $(610 \mathrm{~m})$ to the sideline of the landing point. These initial candidate low-noise profiles were developed primarily using acoustic considerations, but tempered with handling qualities concerns under Instrument Flight Rules (IFR) conditions. A total of nineteen different approach profiles were flown, in addition to the baseline $6 \mathrm{deg}$ approach. Four approaches were selected for presentation in this paper. The first was a standard 6 deg approach that was derived from the Phase 1 test. This approach was determined to be a very comfortable ("workload") approach by the pilots, with excellent handling qualities, and is also very close to a typical FAA noise certification approach for conventional helicopters. For these reasons, the 6 deg approach was selected to be the "baseline" approach against which all other approach profiles would be compared. In addition to the $6 \mathrm{deg}$ approach results, results from a $3 \mathrm{deg}$ and a $9 \mathrm{deg}$ approach, and a 3 deg to 9 deg segmented approach are presented. The approach conditions will first be described in detail, followed by a discussion of the noise footprint characteristics and comparisons with the 6 deg approach profile.

\section{Approach Profiles}

The primary approach profile parameters for the four selected approaches are shown in Figs. 12a through 12d. Each part of the figure presents the altitude, airspeed, and nacelle angle as a function of the uprange distance for a single approach. The initial glideslope was intercepted at a distance of $18,000 \mathrm{ft}(5,490 \mathrm{~m})$ uprange of the landing point for all approaches. A dash-dot line indicates the intended or desired flight path. It should be noted that while the approach profiles were designed using airspeed, they were flown using ground speed. Prevailing tailwinds of approximately 10 to $15 \mathrm{kn}$ persisted during much of this test, resulting in lower airspeeds than the profiles were designed for. All the Phase 2 profiles presented in this paper were flown with tailwinds of about $10 \mathrm{kn}$.

For the 6 deg approach profile (Fig. 12a), the aircraft intercepted the 6 deg glideslope at an altitude of about $1,900 \mathrm{ft}$ $(580 \mathrm{~m})$ with approximately $60 \mathrm{kn}$ airspeed and a nacelle angle of $85 \mathrm{deg}$. This approach was designed for a $70-\mathrm{kn}$ airspeed; however, 10-kn tailwinds resulted in an airspeed of about $60 \mathrm{kn}$. The $85 \mathrm{deg}$ nacelle angle $/ 60 \mathrm{kn}$ condition was maintained until the aircraft was approximately $3,300 \mathrm{ft}$ $(1,005 \mathrm{~m})$ uprange, where the nacelles were rotated to 90 deg and a deceleration to $40 \mathrm{kn}$ was begun. At about $1,800 \mathrm{ft}(549 \mathrm{~m})$ uprange, the aircraft began decelerating to achieve an IGE hover at the landing point. As mentioned earlier, the pilot considered this to be a very comfortable approach.

For the $3 \mathrm{deg}$ approach profile (Fig. 12b), the aircraft intercepted the $3 \mathrm{deg}$ glideslope at an altitude of about $950 \mathrm{ft}$ $(290 \mathrm{~m})$ and followed a nacelle angle/airspeed schedule very different from that of the $6 \mathrm{deg}$ approach. This approach began with a nacelle angle of $60 \mathrm{deg}$ and airspeed of about $100 \mathrm{kn}$. This nacelle angle and airspeed were maintained until the aircraft was $7,500 \mathrm{ft}(2,286 \mathrm{~m})$ uprange, where the nacelles were rotated to $80 \mathrm{deg}$ and a deceleration to $60 \mathrm{kn}$ was initiated. At a distance of about $3,300 \mathrm{ft}(1,005 \mathrm{~m})$ uprange, the nacelles were rotated to $85 \mathrm{deg}$ and a deceleration to $40 \mathrm{kn}$ was initiated. Finally, the nacelles were rotated to $90 \mathrm{deg}$ at the point about $1,800 \mathrm{ft}$ uprange 
and the final deceleration to an IGE hover at the landing point was initiated. The pilot described this approach as "controllable, adequate performance and tolerable workload." However, he also commented he would have preferred to convert to a $90 \mathrm{deg}$ nacelle angle sooner and to be allowed to convert to $95 \mathrm{deg}$ towards the end to decrease the noseup attitude to provide a better visual view of the landing point. Conversions to $95 \mathrm{deg}$ were not allowed, due to the IFR approach constraints and for possible safety considerations in the case of an engine out.

For the $9 \mathrm{deg}$ approach profile (Fig. 12c), the aircraft intercepted the 9 deg glideslope at an altitude of about 2,900 ft $(884 \mathrm{~m})$ and followed the same nacelle angle/airspeed schedule as that of the $6 \mathrm{deg}$ approach. The approach began with approximately $60 \mathrm{kn}$ airspeed and a nacelle angle of 85 deg. At an uprange distance of about $3,300 \mathrm{ft}(1,006 \mathrm{~m})$ the nacelles were rotated to $90 \mathrm{deg}$ and a deceleration to $40 \mathrm{kn}$ was initiated. Deceleration to an IGE hover at the landing point was initiated about $1,800 \mathrm{ft}(549 \mathrm{~m})$ uprange. The pilot considered this to be a comfortable approach all the way in and commented "very controllable, achieved adequate performance, tolerable workload."

The 3 deg to 9 deg segmented approach, shown in Fig. 12d, followed a nacelle angle/airspeed schedule similar to that of the $3 \mathrm{deg}$ approach. It had a glideslope intercept of the initial $3 \mathrm{deg}$ glideslope at an altitude of about 1,250 $\mathrm{ft}$ ( 381 $\mathrm{m}$ ) with approximately $80 \mathrm{kn}$ airspeed and a nacelle angle of $60 \mathrm{deg}$. At a distance of about $4,800 \mathrm{ft}(1,463 \mathrm{~m})$ uprange the nacelles were rotated to $80 \mathrm{deg}$ and a deceleration to about $60 \mathrm{kn}$ was initiated. The guidance provided by the flight director system during this test did not include compensation for the aerodynamic coupling between nacelle rotation and rate of climb due to the rotation of the thrust vector. Just prior to interception of the $9 \mathrm{deg}$ glideslope, at about $2,700 \mathrm{ft}(823 \mathrm{~m})$ uprange and an intended altitude of about $450 \mathrm{ft}(137 \mathrm{~m})$, the aircraft deviated above the intended glideslope path by more than $100 \mathrm{ft}(30 \mathrm{~m})$ due to nacelle rotation. Compensation for nacelle rotation, integrated into the flight director system during a subsequent flight director development program (documented in Ref. 23), was available for the Phase 3 test. At about $2,100 \mathrm{ft}$ $(640 \mathrm{~m})$ uprange, the nacelles were rotated to $85 \mathrm{deg}$ and a deceleration to $40 \mathrm{kn}$ was begun. At about $1,500 \mathrm{ft}(457 \mathrm{~m})$ uprange the nacelles were rotated to $90 \mathrm{deg}$ and the final deceleration to an IGE hover was initiated. The pilot found this approach unacceptable because "the profile keeps too high a nacelle angle for the airspeed .... don't like the (tail) buffeting vibrations on the descent."

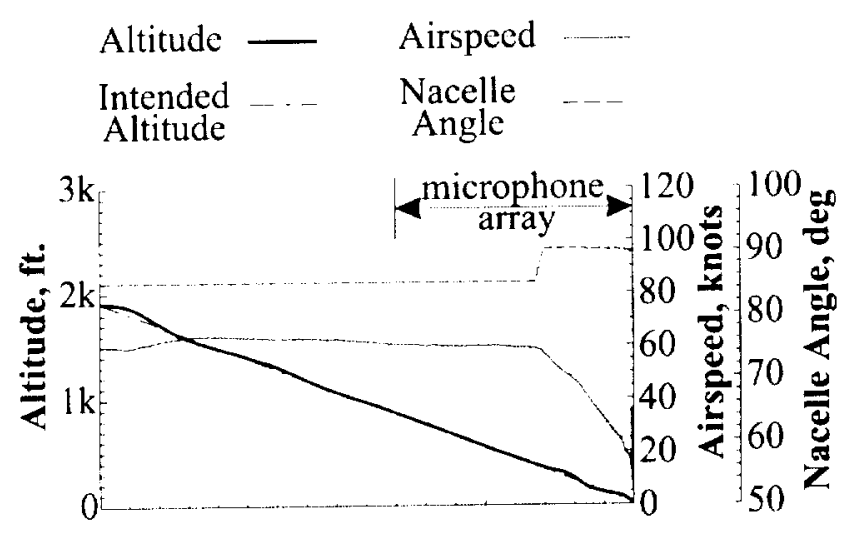

a) $6^{\circ}$ "baseline" approach (early nacelle transition).

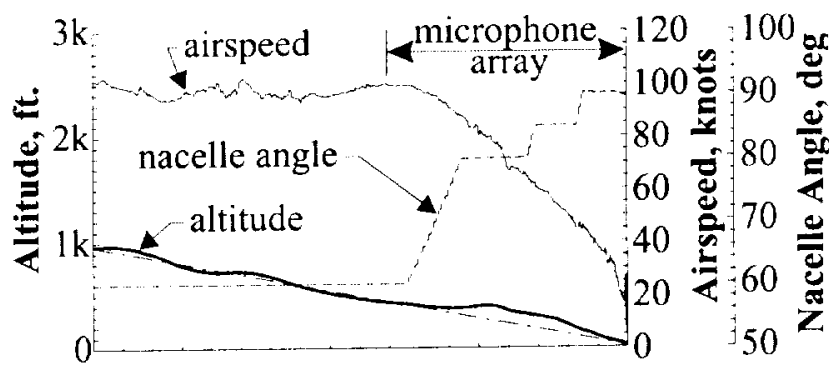

b) $3^{\circ}$ approach (late nacelle transition).

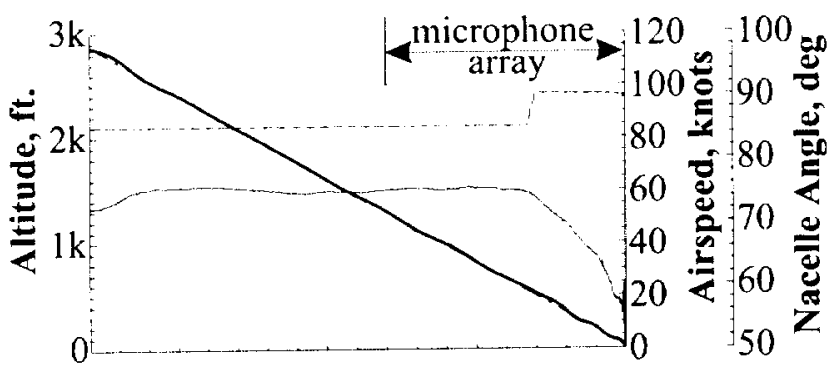

c) $9^{\circ}$ approach (early nacelle transition).

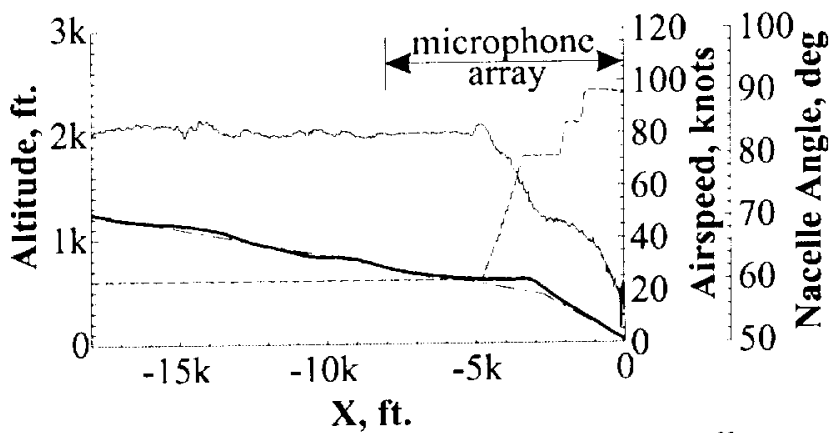

d) $3^{\circ}$ to $9^{\circ}$ segmented approach (late nacelle transition).

Fig. 12. Altitude, airspeed, and nacelle angle schedules as measured during the Phase 2 test. 


\section{Ground Contours}

Fig. 13 shows the characteristics of the resulting noise footprints for the same four approaches presented in Fig. 12. The separation in the contour levels is 5 SELdB and the contour levels are labeled from $A$ to $G$, with $A$ representing the lowest SEL (shown as black in the figure) and G representing the highest SEL (shown as white in the figure). The contour scales for all parts of the figure represent equal values to allow for direct comparisons. Each footprint extends from $1,000 \mathrm{ft}(304 \mathrm{~m})$ downrange to $8,000 \mathrm{ft}(2,440 \mathrm{~m})$ uprange of the landing point and spans up to $2,000 \mathrm{ft}(610$ $\mathrm{m})$ to either side of the landing point, covering an area of more than 650 acres $\left(2.6 \mathrm{~km}^{2}\right)$. The $X V-15$ approached from the left in the figure, along a line at $Y=0$, coming to an IGE hover at about $20 \mathrm{ft}(6 \mathrm{~m})$ AGL over the hover pad located at $X=Y=0$. The noise footprints are most useful to provide a qualitative assessment of the noise abatement potential of the different approach profiles. The contour data will be presented in other formats later in this section that will provide for an easier quantitative assessment.

The noise footprint for the $6 \mathrm{deg}$ "baseline" approach is presented in Fig. 13a. The highest SEL contour is located along the flight path between approximately 200 and $500 \mathrm{ft}(60$ and $150 \mathrm{~m})$ uprange of the hover pad $(-500 \leq X \leq-200)$ and extends about $150 \mathrm{ft}(46 \mathrm{~m})$ to the sidelines. The maximum SEL is not located about the hover pad, due to a combination of the microphone distribution around the hover pad and the linear interpolation technique between the measurement locations used by the graphics software. Safety concerns, as well as rotor-downwash-generated wind noise, precluded locating a microphone on the hover pad. In general, the maximum levels are located about the hover point and decrease rapidly with increasing sideline distance and with increasing downrange distance. The contours decrease least rapidly along the flight path uprange of the hover point, i.e., the area over which the aircraft actually flies. More specifically, the $\mathrm{F}$ contour level extends from about $X=0$ to $X=-1,000$ and about $250 \mathrm{ft}(76 \mathrm{~m})$ to both sidelines with a narrow "tail" that extends to about $1,700 \mathrm{ft}(518 \mathrm{~m})$ uprange. Each successively lower SEL contour is a little larger, extending a little further in front of and to the sides of the hover pad. Uprange along the flight path, the contour "tails" increase in both length and width with decreasing contour level. For the contour levels of D and below, the contour "tails" extend uprange beyond the area of the measured noise footprint.

Fig. 13b shows the noise footprint for the $3 \mathrm{deg}$ approach. Compared to the $6 \mathrm{deg}$ approach, the contour levels generally fall off more rapidly with increasing distance from the
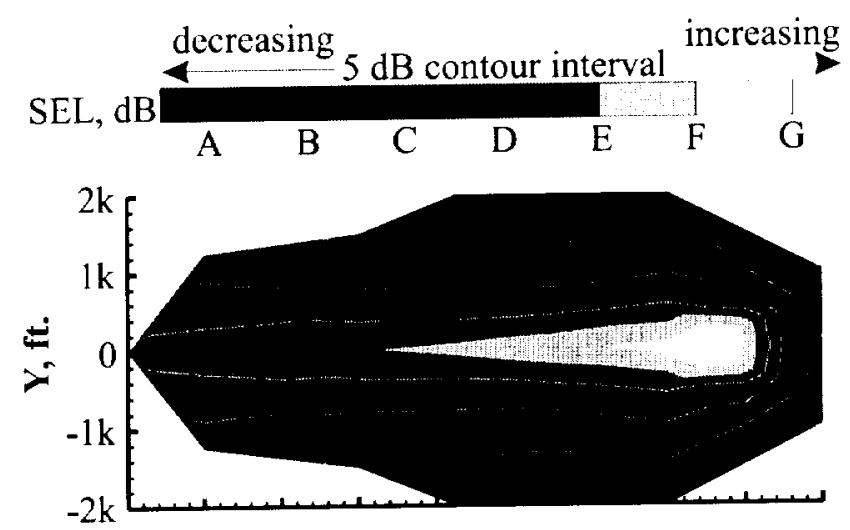

a) $6^{\circ}$ "baseline" approach.

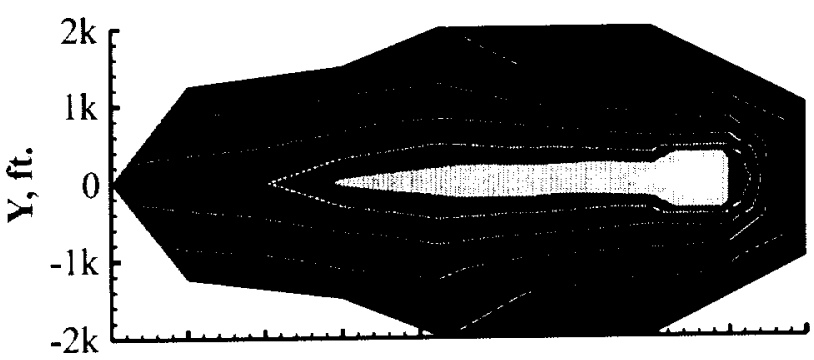

b) $3^{\circ}$ approach.

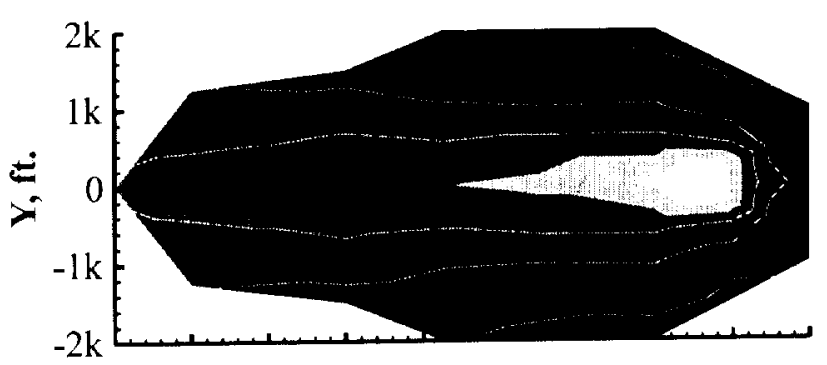

c) $9^{\circ}$ approach.

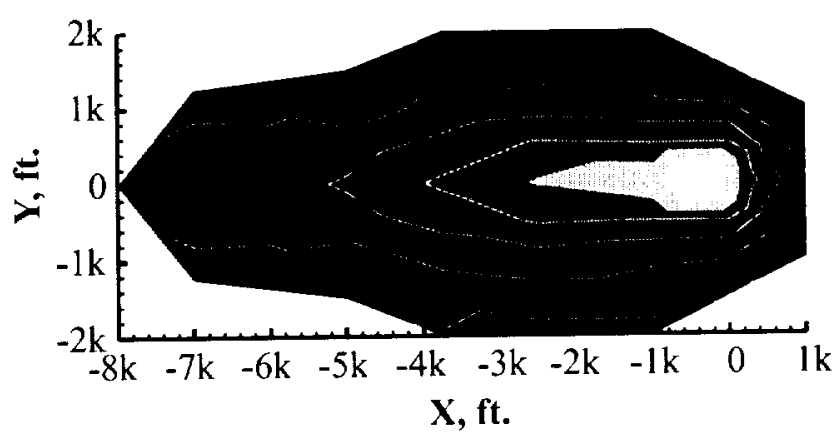

d) $3^{\circ}$ to $9^{\circ}$ approach.

Fig. 13. SEL ground contours as measured during the Phase 2 test. 
landing point. While the E contour level extends about 500 $\mathrm{ft}(150 \mathrm{~m})$ further uprange, the $\mathrm{D}$ contour level has been shortened significantly and is contained within the boundaries of the measurement area. For the SEL contour levels below $E$, the decreased sideline width far uprange indicates that the uprange lengths of these contours have also been significantly decreased. This $3 \mathrm{deg}$ approach appears to besomewhat less noisy compared to the $6 \mathrm{deg}$ approach and in fact the average SEL for all microphones has been reduced by $3.3 \mathrm{~dB}$.

The noise footprint for the $9 \mathrm{deg}$ approach is presented in Fig. 13c. Compared to the $6 \mathrm{deg}$ approach, the contour levels generally fall off less rapidly with increasing distance from the landing point. For this approach, the $E$ and $F$ contour levels are a little smaller, while all the contour levels below $\mathrm{E}$ are somewhat larger. This $9 \mathrm{deg}$ approach appears somewhat louder than the $6 \mathrm{deg}$ approach, even though the aircraft was at a higher altitude and thus a greater distance from the microphones. The average SEL for all microphones has increased by $1.5 \mathrm{~dB}$ compared to the 6 deg approach.

The approach footprint for the $3 \mathrm{deg}$ to $9 \mathrm{deg}$ segmented approach is presented in Fig. 13d. All SEL contour levels for this approach are smaller when compared to those for the $6 \mathrm{deg}$ approach. In fact, the contour levels of $\mathrm{E}$ and below are significantly smaller and contour levels $C$ through $G$ are all completely contained within the measurement area. This approach appears to be the quietest approach presented with a reduction in the average SEL of $3.6 \mathrm{~dB}$.

\section{Average Sound Exposure Levels}

A more quantitative way to assess the SEL differences for the different approach profiles is to compare the average SEL (AVGSEL) for all microphones, or for a given subset of the microphones. Fig. 14a and Table 1 identify the different microphone groupings which were averaged and presented here. Fig. $14 \mathrm{~b}$ presents the difference between the average SEL for the $6 \mathrm{deg}$ approach and the average SEL for each of the other approaches as a function of the microphone group. A negative DAVGSEL means that the average SEL has been reduced compared to the $6 \mathrm{deg}$ baseline approach. This figure shows that the $9 \mathrm{deg}$ approach had the highest levels for all microphone groups presented with an DAVGSEL of between 1 and $2 \mathrm{~dB}$. The $3 \mathrm{deg}$ approach is the quietest approach around the landing point (group A) with an DAVGSEL of about $-5.5 \mathrm{~dB}$. This may be because the lower rate of descent requires less of a flare at the end of the approach to achieve a hover condition. The $3 \mathrm{deg}$ approach is a little more than $3 \mathrm{dBSEL}$ quieter than the baseline approach for the average SEL using all the microphones (group B), while groups C and D show more modest noise
Table 1. Microphone grouping ID (Phase 2 test).

\begin{tabular}{|c|l|}
\hline Microphone group ID & \multicolumn{1}{|c|}{ Microphones used in average } \\
\hline A & $\begin{array}{l}\text { All microphones between 1,000 } \\
\text { feet downrange and 1,000 feet } \\
\text { uprange of the landing point }\end{array}$ \\
\hline B & All microphones \\
\hline C & $\begin{array}{l}\text { All microphones between 3,000 } \\
\text { and } 8,000 \text { feet uprange of the } \\
\text { landing point }\end{array}$ \\
\hline D & $\begin{array}{l}\text { All microphones between } 6,000 \\
\text { and } 8,000 \text { feet uprange of the } \\
\text { landing point }\end{array}$ \\
\hline
\end{tabular}

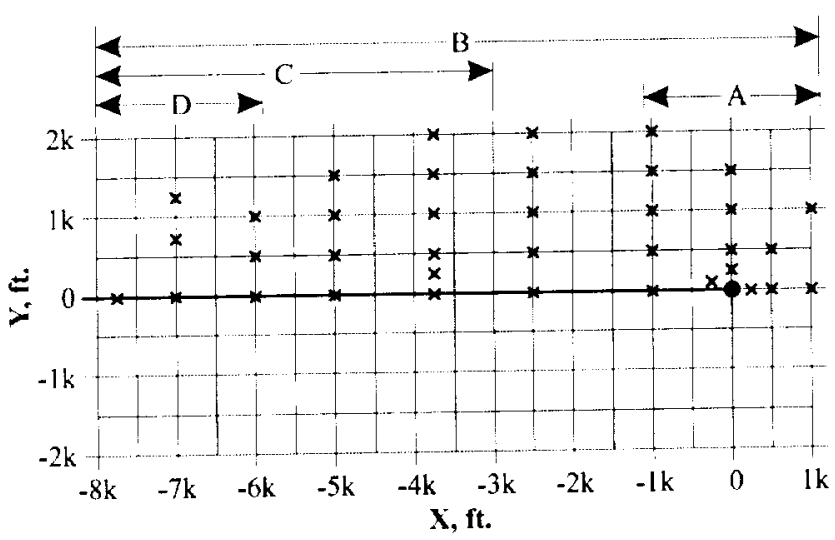

a) Microphone group ID.

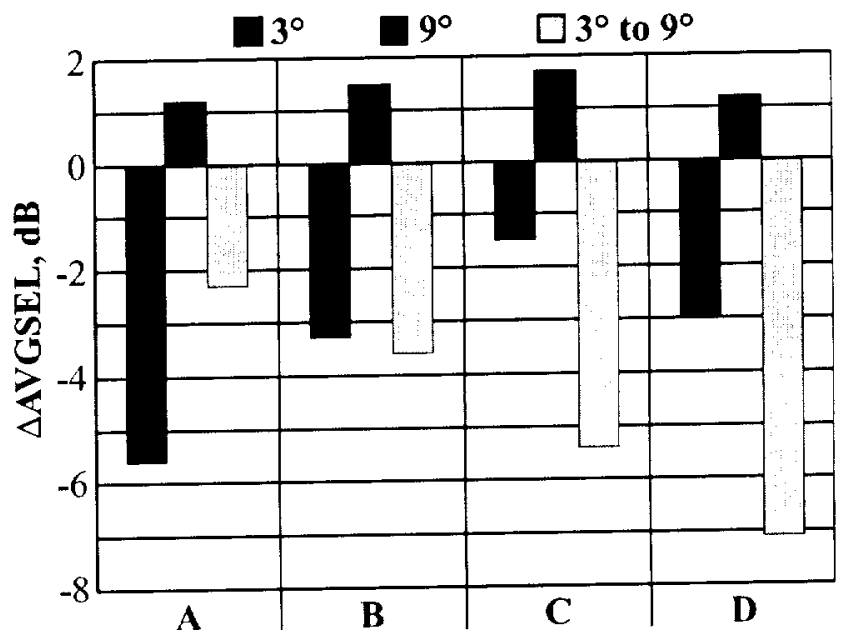

b) SEL difference from $6^{\circ}$ baseline approach.

Fig. 14. Average SEL differences for selected microphone groupings, as measured during the Phase 2 test. 
reductions of about -1.5 and $-3 \mathrm{dBSEL}$, respectively. The 3 deg to 9 deg approach shows the greatest noise reduction for all microphone groups except around the hover pad. The noise benefits for this approach increase as you move to the progressively uprange microphone sets. For group $\mathrm{D}$, the average SEL has been reduced by more than $7 \mathrm{dBSEL}$ compared to the $6 \mathrm{deg}$ baseline approach. This figure indicates that the $3 \mathrm{deg}$ to $9 \mathrm{deg}$ approach provides the greatest noise abatement for all areas of the measured footprint, except near the landing point.

\section{Contour Areas}

Another way to assess the noise abatement potential of the different approach profiles is to compare the ground contour areas exposed to a given noise level. Fig. 15 presents the contour area, in percentage of the total measurement area, as a function of the relative SEL for the four different approaches. At the lowest levels, all the approaches converge to $100 \%$ of the measurement area, while at the highest levels all approaches eventually converge to $0 \%$ of the measurement area. For a given contour level, the largest differences in area between the different approaches are found at the lowest noise levels while the smallest differences are found at the highest noise levels. This figure clearly shows that the 9 deg approach had the largest contour areas for all but the highest levels. The $3 \mathrm{deg}$ approach has the smallest areas at the lower levels while the $3 \mathrm{deg}$ to $9 \mathrm{deg}$ segmented approach has smallest areas at the higher levels. This figure also clearly demonstrates that the $3 \mathrm{deg}$ approach and the 3 deg to 9 deg segmented approach are the quietest of the four runs considered here. Again, it should be noted that, although for convenience the approach procedures are denoted by calling out their glideslopes, the acoustic characteristics are strongly influenced by the nacelle angle/airspeed schedule as well as glideslope.

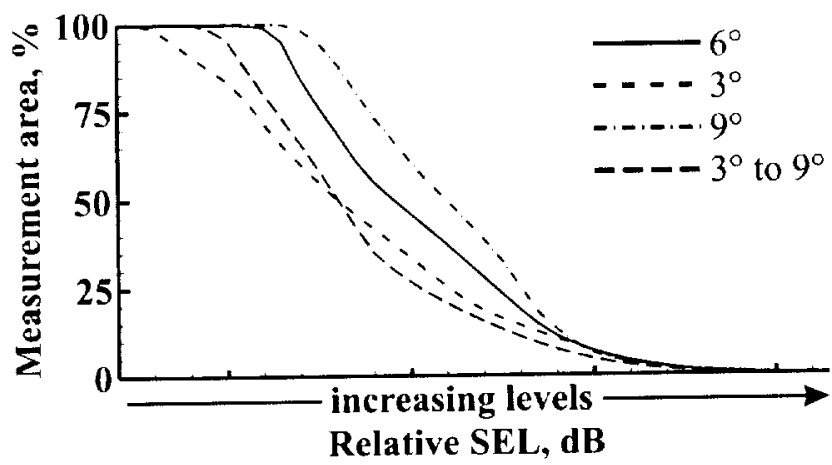

Fig. 15. SEL ground contour areas as a percentage of totoal measurement area, as measured during the Phase 2 test.
Impact of the Flight Director and Handling Qualities on Noise Abatement Procedures

During Phase 2 testing, the profiles were flown as IFR approaches using the newly developed flight director. This allowed much more repeatable, precise profiles, but ones that were necessarily limited by the pilot's IFR workload. To allow enough time for the pilot to assimilate the flight director's visual cues and translate them into control inputs, a time delay, or buffer, of approximately 5 seconds had to be allowed for after each pilot instruction. This buffer produced an elongated approach compared to Visual Flight Rules (VFR) approaches, thus limiting the terminal area noise-reduction potential. Improvements in control systems and future flight directors will allow the quieter low-nacelle flight operations to be brought nearer the terminal area. As higher levels of control augmentation and other improvements are incorporated, future pilot workload will be reduced, allowing precise, repeatable approaches to be made in a shorter time/distance interval. This will allow approaches that tend more toward the shorter VFR-type approaches. Within the next 10 years, civil tiltrotor operations will make use of the information derived from both VFRand IFR-type acoustic testing to combine handling qualities and acoustic constraints in an automated, efficient flight director. This will allow the noise-reduction potential of the tiltrotor to be applied in precise, repeatable approaches to the public benefit.

\section{Summary of Phase 2 Noise Abatement Approaches}

All of the above results lead the authors to make the following assessments. The $3 \mathrm{deg}$ approach and the $3 \mathrm{deg}$ to $9 \mathrm{deg}$ segmented approach were the quietest approaches tested during the Phase 2 test. This is primarily due to the fact that these approaches maintained a lower $60 \mathrm{deg}$ nacelle angle until about one mile $(1.6 \mathrm{~km})$ from the landing point. The combination of nacelle angle, airspeed, and glideslope appear to orient the rotor tip-path-planes to a condition that avoids blade-vortex interactions (BVI). The $6 \mathrm{deg}$ and 9 deg approaches began at a nacelle angle of $80 \mathrm{deg}$ from nearly 3 miles $(48 \mathrm{~km})$ out, thus putting the rotors into a flight condition more likely to generate BVI noise. The 3 deg approach was the quietest around the hover pad, probably due to the lower descent rate requiring less of a decelerating flare to achieve hover at the landing point. The $3 \mathrm{deg}$ to $9 \mathrm{deg}$ segmented approach was much quieter at the far uprange distances, probably because the aircraft was on the quieter $3 \mathrm{deg}$ glideslope but about $300 \mathrm{ft}(91 \mathrm{~m})$ higher in altitude than the $3 \mathrm{deg}$ approach, due to the steeper $9 \mathrm{deg}$ segment towards the end of the approach. For the final portion of the approach, from about $2,500 \mathrm{ft}(762 \mathrm{~m})$ uprange to the landing point, the $3 \mathrm{deg}$ to $9 \mathrm{deg}$ segmented approach was quieter on and around the centerline of the flight path, 
while the 3 deg approach was quieter to the sidelines. This was probably because the $3 \mathrm{deg}$ to $9 \mathrm{deg}$ approach had transitioned to the noisier condition of the $9 \mathrm{deg}$ glideslope. Comparing the $3 \mathrm{deg}, 6 \mathrm{deg}$, and $9 \mathrm{deg}$ approaches, the $6 \mathrm{deg}$ approach tended to be the loudest on centerline at all uprange distances measured; however, this difference was usually quite small. The noise levels to the sidelines at all uprange distances increased with increasing glideslope angle. Noise levels around the landing point also increased with increasing glideslope angle. Overall, the 9 deg approach was the loudest and the $3 \mathrm{deg}$ approach was the quietest.

\section{PHASE 3 RESULTS}

The purpose of the Phase 3 test was to quantify the noise reduction provided by optimized noise abatement approaches. The design process for the approach profiles that were tested used results from the Phase 1 and Phase 2 tests while fully coupling noise reduction with handling qualities. The flight director system was modified in an attempt to compensate for the aerodynamic coupling between nacelle rotation and rate of climb due to the rotation of the thrust vector. Noise footprints were measured for a rectangular grid that extended from $1,000 \mathrm{ft}$ to $9,000 \mathrm{ft}(304 \mathrm{~m}$ to $2,743 \mathrm{~m})$ uprange and $2,000 \mathrm{ft}(610 \mathrm{~m})$ to the sideline of the landing point. A total of eight different approach profiles were flown, in addition to the $6 \mathrm{deg}$ baseline approach. The 6 deg baseline approach profile tested in Phase 3 was, for all practical purposes, identical to the one flown during the Phase 2 test (Fig. 12a). Two low-noise approaches profiles have been selected for presentation here, the $3 \mathrm{deg}$ approach and a $3 \mathrm{deg}$ to $9 \mathrm{deg}$ segmented approach. Each of these approaches was flown six times during this test, and the acoustic values presented are the average values over the six runs. These approach profiles were selected for presentation because the $3 \mathrm{deg}$ profile provided significant and uniform noise reduction over the entire measurement area, while the 3 deg to 9 deg profile provided the greatest noise reductions at the areas farther uprange. The approach conditions and the average noise footprints are presented, followed by comparisons to the $6 \mathrm{deg}$ baseline approach.

\section{Approach Profiles}

Measured altitude, airspeed, and nacelle angle schedules for one run for each of the two selected approach profiles are shown in Fig. 16. While the approach profiles for the six runs used in the calculation of the average noise levels were nearly identical, slight variations did exist. Comparison of the six runs showed that altitude variations were generally less than $\pm 25 \mathrm{ft}( \pm 7.6 \mathrm{~m})$, airspeed variations were generally less than $\pm 3 \mathrm{kn}$, and variations of less than $\pm 100 \mathrm{ft}(30 \mathrm{~m})$ in the uprange distance at which nacelle angle changes were

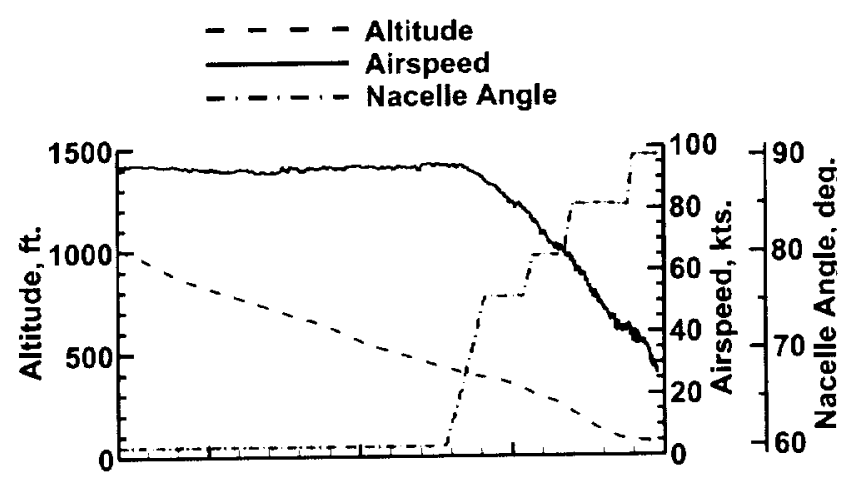

a) $3^{\circ}$ approach.

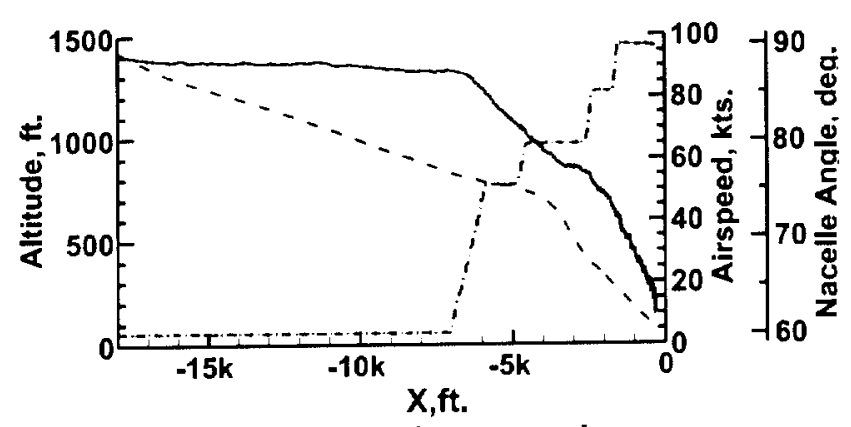

b) $3^{\circ}$ to $9^{\circ}$ approach.

Fig. 16. Altitude, airspeed, and nacelle angle schedules as measured during the Phase 3 test.

initiated. For the Phase 3 approaches, the initial glideslope was intercepted at a distance of $18,000 \mathrm{ft}(5,486 \mathrm{~m})$ uprange of the landing point. All Phase 3 approaches were flown with a headwind component of between 5 and $15 \mathrm{kn}$.

The $3 \mathrm{deg}$ approach profile characteristics are presented in Fig. 16a. The aircraft intercepted the $3 \mathrm{deg}$ glideslope at an altitude of about $950 \mathrm{ft}(290 \mathrm{~m})$ with a nacelle angle of 60 deg and airspeed of about $95 \mathrm{kn}$. This nacelle angle and airspeed were maintained until the aircraft was about 7,000 ft $(2,134 \mathrm{~m})$ uprange, where the nacelles were rotated to 75 deg and a nearly constant deceleration rate, sufficient to achieve a hover condition over the landing point, was initiated. The nacelles were rotated in $5 \mathrm{deg}$ increments to 80 , 85 , and $90 \mathrm{deg}$ at uprange distances of about 4,600,3,200, and $1,200 \mathrm{ft}(1,400,975$, and $366 \mathrm{~m})$, respectively. The approach was terminated at an uprange distance of about $300 \mathrm{ft}$ $(91 \mathrm{~m})$ when the aircraft was at an altitude of about $50 \mathrm{ft}$ $(15 \mathrm{~m})$ and airspeed of about $25 \mathrm{kn}$.

The $3 \mathrm{deg}$ to $9 \mathrm{deg}$ segmented approach profile characteristics are presented in Fig. 16b. This approach had a glideslope intercept of the initial $3 \mathrm{deg}$ glideslope at an altitude of about $1,400 \mathrm{ft}(427 \mathrm{~m})$ with an airspeed of $93 \mathrm{kn}$ 
and a nacelle angle of $60 \mathrm{deg}$. At a distance of about 7,000 $\mathrm{ft}(2,134 \mathrm{~m})$ uprange, the nacelles were rotated to $75 \mathrm{deg}$ and a deceleration to about $55 \mathrm{kn}$ was initiated. The nacelles were then rotated to $80 \mathrm{deg}$ at an uprange distance of about $5,000 \mathrm{ft}(1,524 \mathrm{~m})$, followed by the $9 \mathrm{deg}$ glideslope intercept at an uprange distance of about $4,000 \mathrm{ft}(1,219 \mathrm{~m})$. At about $2,500 \mathrm{ft}(762 \mathrm{~m}$ ) uprange, the nacelles were rotated to $85 \mathrm{deg}$ and the final deceleration to a hover condition was initiated. The final nacelle rotation to $90 \mathrm{deg}$ was initiated at about $1,800 \mathrm{ft}(549 \mathrm{~m})$ uprange of the landing point. The approach was terminated at an uprange distance of about $300 \mathrm{ft}(91 \mathrm{~m})$ when the aircraft was at an altitude of less than $100 \mathrm{ft}(30 \mathrm{~m})$ and airspeed of about $10 \mathrm{kn}$.

As is evident in Fig. 16, the nacelle angle/airspeed schedules are very similar for these two quiet approaches, each being significantly different from the $6 \mathrm{deg}$ baseline approach shown earlier (Fig. 12a).

\section{Ground Contours}

Fig. 17 shows the average noise footprints for the approach profiles presented in Fig. 16. The contour format is identical to that of the earlier contours (Fig. 13), though the shape of the contours is different due to the microphone array layout differences between the Phase 2 and Phase 3 tests. Fig. 18 presents contours of the SEL difference from the average 6 deg baseline approach levels. Four runs were used in the calculation of the average SEL values for the $6 \mathrm{deg}$ baseline approach. A negative contour level indicated a reduction in the noise level compared to the $6 \mathrm{deg}$ baseline approach while a positive value indicates an increase in the noise level. Because noise measurements were made directly beneath and to one side of the aircraft flight path only, these noise footprints should be symmetric about $Y=0$. However, these footprints are not exactly symmetric due to the linear interpolation scheme used by the plotting program. Each noise footprint in these two figures extend from 1,000 $\mathrm{ft}$ to $9,000 \mathrm{ft}(304$ to $2,743 \mathrm{~m}$ ) uprange of the landing point and span to $2,000 \mathrm{ft}(610 \mathrm{~m})$ to either side of the landing point, covering an area of 735 acres $\left(2.97 \mathrm{~km}^{2}\right)$. The XV-15 approached from the left in the figure, along a line at $Y=0$, and held the desired approach conditions until reaching a point approximately $300 \mathrm{ft}(91 \mathrm{~m})$ uprange $(X=-300 \mathrm{ft})$ of the landing point.

The noise footprint for the $3 \mathrm{deg}$ approach is presented in Fig. 17a. The highest SEL contour (G) is located along the flight path between approximately 1,000 and 3,700 $\mathrm{ft}$ (304 and $1,128 \mathrm{~m}$ ) uprange of the landing point $(-1,000 \leq X \leq-3,700)$ and extends about $200 \mathrm{ft}(60 \mathrm{~m})$ to the sidelines at its widest point, which was located at the line of microphone 2,600 ft $(793 \mathrm{~m})$ uprange. This "hot spot" is just ahead of the aircraft location when the nacelles were moved from $80 \mathrm{deg}$ to $85 \mathrm{deg}$ and is likely due to the occurrence of blade-vortex interactions at this airspeed/nacelle angle/descent rate combination. In general, the levels decrease rapidly with increasing sideline distance. The contour levels decrease least rapidly along the flight path. More specifically, the F contour level extends about one mile (1.6 $\mathrm{km})$ uprange with a maximum width of about $700 \mathrm{ft}(213 \mathrm{~m})$ while the $E$ contour extends nearly $8,000 \mathrm{ft}(2,440 \mathrm{~m})$ uprange with a maximum width of about $1,100 \mathrm{ft}(335 \mathrm{~m})$. The $\mathrm{D}$ and $\mathrm{C}$ contour levels appear to extend well beyond the measurement location furthest uprange.

The noise footprint for the $3 \mathrm{deg}$ to $9 \mathrm{deg}$ segmented approach is presented in Fig. $17 \mathrm{~b}$. The maximum contour level (G) extends to $2,600 \mathrm{ft}(793 \mathrm{~m}$ ) uprange and the width of this contour increases with decreasing uprange distance. The $F$, $E$, and $D$ contour levels extend to about $3,800,5,200$, and $7,700 \mathrm{ft}(1,158,1,585$, and $2,347 \mathrm{~m})$ uprange, respectively, while the $\mathrm{C}$ contour level extends beyond the furthest uprange measurement location.

Fig. 18a shows an area along the flight path between about 1,900 and $4,200 \mathrm{ft}(579$ and $1,280 \mathrm{~m})$ uprange, with a
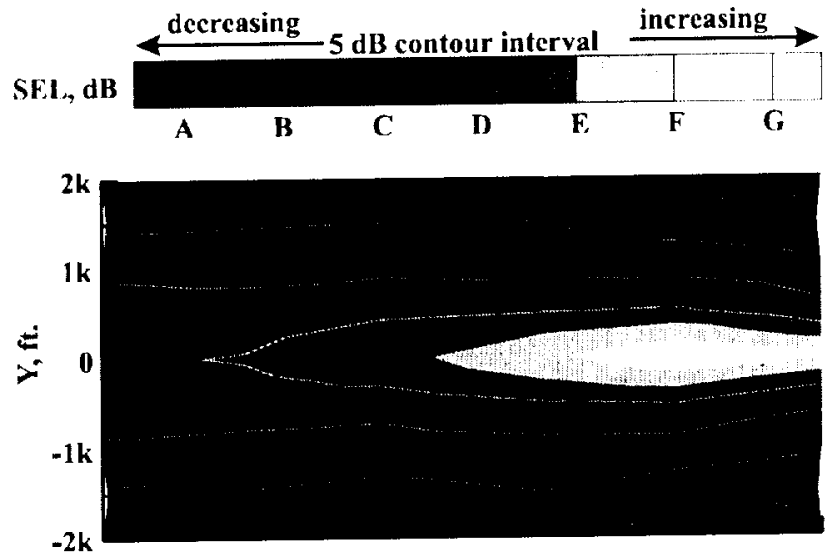

a) $3^{\circ}$ approach.

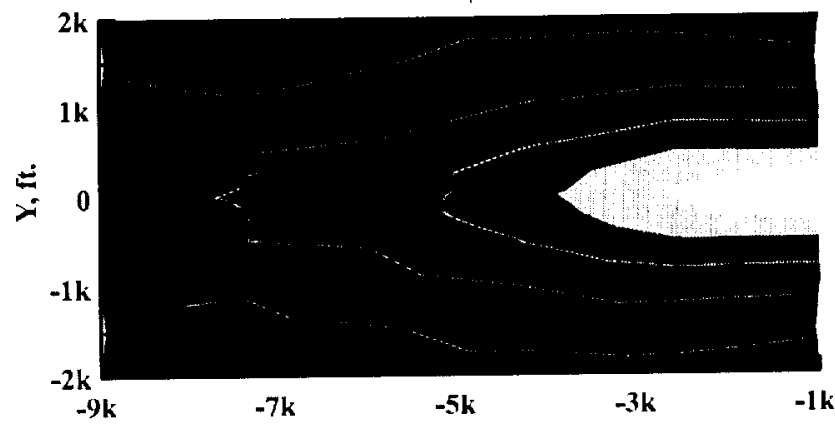

b) $3^{\circ}$ to $9^{\circ}$ approach.

Fig. 17. SEL ground contours as measured during the Phase 3 test. 
maximum width of $500 \mathrm{ft}(152 \mathrm{~m})$, where the levels are as much as 2 SELdB higher than measured for the 6 deg baseline approach. A very small area directly beneath the flight path at 2,600 $\mathrm{ft}(793 \mathrm{~m})$ uprange shows an increase of greater than $2 \mathrm{SELdB}$. Around this pocket of increased noise levels is an area where the levels have decreased by as much as 4 SELdB. The majority of the area contained in this footprint shows a noise reduction of between 4 and 6 SELdB with small pockets showing reductions of greater than 6 SELdB.

Fig. $18 \mathrm{~b}$ presents a footprint of the average SEL difference between the $3 \mathrm{deg}$ to $9 \mathrm{deg}$ segmented approach and the 6 deg baseline approach. The figure shows areas of increased noise levels between 1,000 and 3,500 ft (304 and $1,067 \mathrm{~m}$ ) uprange, centered along lines $500 \mathrm{ft}(152 \mathrm{~m})$ to either side of the flight-track centerline. The level of noise reduction increases with increasing uprange distance with the maximum noise reductions occurring along the flightpath centerline. A maximum noise reduction of greater than $10 \mathrm{SELdB}$ is shown along the flightpath centerline between about 6,300 and $8,800 \mathrm{ft}(1,920$ and $2,682 \mathrm{~m})$ uprange.
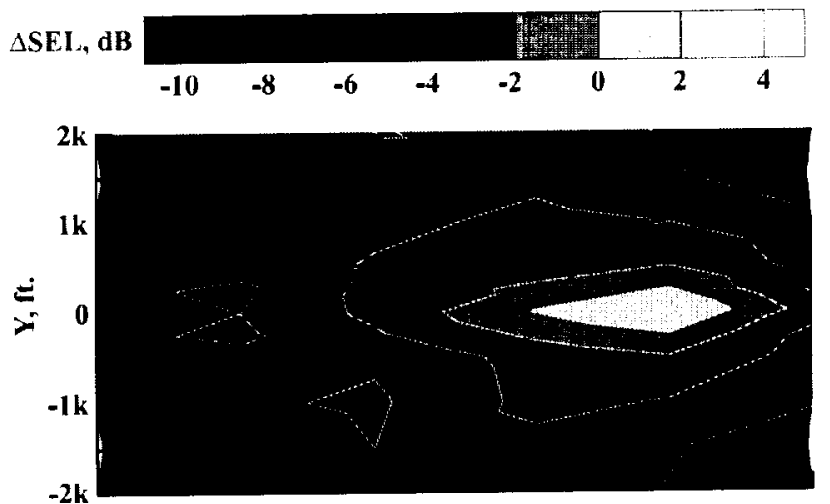

a) $3^{\circ}$ approach.

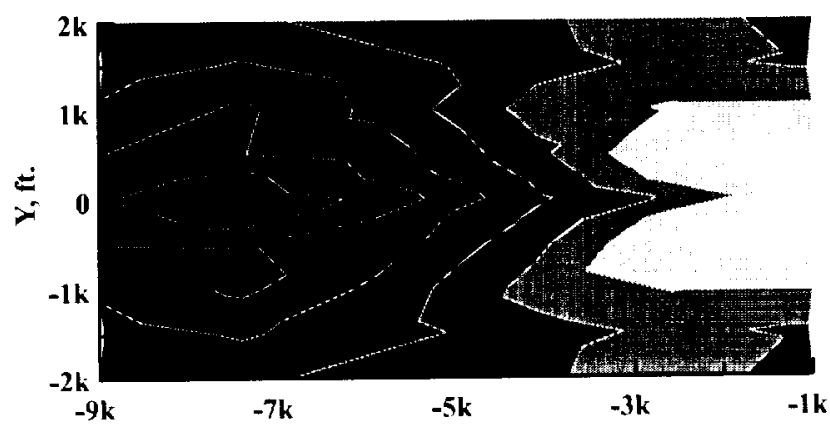

b) $3^{\circ}$ to $9^{\circ}$ approach.

Fig. 18. Contours of the difference from the 6-deg baseline approach SEL, as measured during the Phase 3 test.

\section{Average Sound Exposure Levels}

A more quantitative assessment of the noise reductions is presented in Fig. 19. This figure presents the difference between the average SEL for the $6 \mathrm{deg}$ approach and the average SEL for the two approach profiles of Fig. 16, for a number of different microphone groups, as labeled directly beneath the bar graph. A negative DAVGSEL means that the average SEL has been reduced compared to the 6 deg baseline approach. Compared to the $6 \mathrm{deg}$ baseline approach, the 3 deg approach provides nearly 4.5 SELdB noise reduction and the $3 \mathrm{deg}$ to $9 \mathrm{deg}$ approach provides about $3.8 \mathrm{SELdB}$ noise reduction when averaged over all the microphones used during this test (far left bars, labeled "All"). Moving from left to right in the figure, the next pair of bars show that the $3 \mathrm{deg}$ to $9 \mathrm{deg}$ approach provides the greatest noise reduction along the centerline, almost $6 \mathrm{SELdB}$, compared to about $2.5 \mathrm{SELdB}$ for the $3 \mathrm{deg}$ approach. Averaging the centerline microphones located between 4,000 and $9,000 \mathrm{ft}$ $(1,219$ and $2,743 \mathrm{~m})$ uprange, the $3 \mathrm{deg}$ to $9 \mathrm{deg}$ approach provides nearly 9 SELdB noise reduction while the $3 \mathrm{deg}$ approach provides only $3.7 \mathrm{SELdB}$ noise reduction. The next four pairs of bars show the average noise reduction starting at the far end of the noise footprint $(9,000 \mathrm{ft}$ $[2,743 \mathrm{~m}]$ uprange), progressively including areas closer to the landing point with each successive pair. The first pair averages the SEL from the microphones in the two farthest

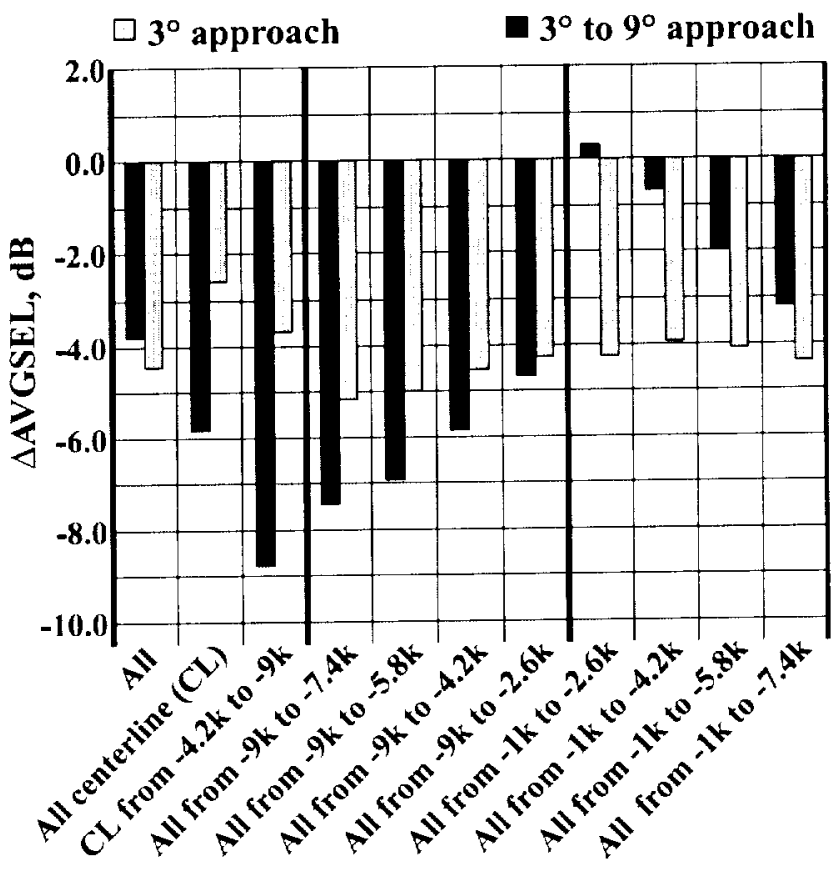

Microphone grouping

Fig. 19. Average SEL difference from the 6-deg baseline approach for different microphone groups, as measured during the Phase 3 test. 
uprange lines of microphones, located 9,000 and $7,400 \mathrm{ft}$ $(2,743$ and $2,256 \mathrm{~m})$ uprange. Each of the next three pairs progressively includes the next line of microphones closer to the landing point $(5,800,4,200$, and $2,600 \mathrm{ft}[1,768,1,280$, and $793 \mathrm{~m}$ ] uprange). This set shows the trend of decreasing noise reduction with increasing area when starting at the end of the noise footprint farthest from landing point. The $3 \mathrm{deg}$ to $9 \mathrm{deg}$ approach provides an average of $7.4 \mathrm{SELdB}$ noise reduction when including the area from 7,400 to $9,000 \mathrm{ft}$ $(2,256$ and $2,743 \mathrm{~m})$ uprange, and $4.7 \mathrm{SELdB}$ noise reduction when including the area from 2,600 to $9,000 \mathrm{ft}$ ( 793 to $2,743 \mathrm{~m}$ ) uprange. The $3 \mathrm{deg}$ approach shows the same trend as the 3 deg to $9 \mathrm{deg}$ approach over these same areas, but provides less noise reduction, decreasing from $5.2 \mathrm{SELdB}$ to $4.3 \mathrm{SELdB}$ noise reduction. The next set of four pairs of bars is similar to the previous set, except that it includes the areas starting closest to the landing point and progressive includes areas farther from the landing point, as indicated in the figure. The first pair, which includes the area from 1,000 to $2,600 \mathrm{ft}$ (304 to $793 \mathrm{~m}$ ) uprange, shows that the 3 deg approach provided 4.2 SELdB noise reduction while the $3 \mathrm{deg}$ to $9 \mathrm{deg}$ approach had a slightly increased noise level. Noise reduction provided by the $3 \mathrm{deg}$ to $9 \mathrm{deg}$ approach increased with increasing uprange area with about 3.2 SELdB noise reduction over the area from 1,000 to $7,400 \mathrm{ft}$ ( 304 to $2,256 \mathrm{~m}$ ) uprange. The $3 \mathrm{deg}$ approach held a relatively constant noise reduction of about 4 SELdB over all the areas included in this set.

\section{Use of Drag Flaps}

Poor engine power response and high nose up pitch attitudes during the initial powered-lift portion ( $60 \mathrm{deg}$ nacelle angle) of steep, low-powered descents resulted in less than desirable handling qualities ratings. Increasing the flap position from the normal maximum setting of $40 \mathrm{deg}$ to the vehicle limit of $75 \mathrm{deg}$ would increase the nosedown pitching moment and increase the aerodynamic drag. Increased drag requires increased thrust and, hence, increased power to maintain the same airspeed, potentially moving the engine power into a better response region. In addition, the increased thrust in the $X$-direction will alter the rotor tip-pathplane and rotor wake geometry, thus altering the BVI noise characteristics (Ref. 26).

Almost all XV-15 testing, including the Phase 1 and Phase 2 acoustics tests discussed in this paper, has been done using a maximum flap setting of $40 \mathrm{deg}$ because earlier testing revealed increased hover downloads with the $75 \mathrm{deg}$ flap position. One approach profile, identified during profile development and confirmed early in the Phase 3 test, was selected for testing at the $75 \mathrm{deg}$ flap setting. This was the first time in many years the $\mathrm{XV}-15$ had been flown at this flap setting. Pilot comments during the flight immediately confirmed the desirability of full flap use. At $90 \mathrm{kn}$ and $60 \mathrm{deg}$ nacelle angle, the body attitude was reduced from an uncomfortable 8 deg with 40 deg flaps to an acceptable 3 deg with $75 \mathrm{deg}$ flaps. The post-flight debrief revealed several additional benefits. Tail buffet was reduced from "moderate" to "minimal." Further, sloppy lateral control that occurred with the high body pitch attitude and low power setting was immediately tightened up, resulting in greatly reduced pilot attention to this control function, thus reducing pilot workload throughout the required operation. In addition, the $75 \mathrm{deg}$ flap setting provided an average noise reduction of approximately 1 SELdB compared to the 40 deg flap setting. After this point all Phase 3 approach profiles, with the exception of the $3 \mathrm{deg}$ and the $6 \mathrm{deg}$ baseline approach profiles, were flown using the $75 \mathrm{deg}$ flap position.

\section{Summary of Phase 3 Noise Abatement Approaches}

The purpose of the Phase 3 test was to quantify the noise reduction potential, compared to the $6 \mathrm{deg}$ baseline approach, of optimized noise abatement approach profiles that fully coupled noise reduction with handling qualities concerns. Eight different noise abatement approach profiles, in addition to the $6 \mathrm{deg}$ baseline approach profile, were flown repeatedly to obtain statistical confidence in the results. The $3 \mathrm{deg}$ approach profile and a $3 \mathrm{deg}$ to $9 \mathrm{deg}$ approach profile were selected for presentation in this paper. The $75 \mathrm{deg}$ flap setting was found to greatly improve the handling quality characteristics of the $3 \mathrm{deg}$ to $9 \mathrm{deg}$ approach profile, while the 40 deg flap setting provided adequate handling quality characteristics for the $3 \mathrm{deg}$ approach profile. Both these approach profiles were rated to have acceptable handling qualities for commercial passenger operations. The $3 \mathrm{deg}$ approach profile provided a very uniform noise reduction over much of the measured footprint area. A 4 to $6 \mathrm{SELdB}$ noise reduction was measured over most of the footprint area, with small areas showing greater than of 6 SELdB noise reduction. A small area, between 2,000 and $4,000 \mathrm{ft}$ ( 610 and $1,219 \mathrm{~m}$ ) uprange and extending from the centerline to as much as $500 \mathrm{ft}(152 \mathrm{~m})$ to the sideline, showed increased noise levels of no more than about 2 SELdB. The 3 deg to 9 deg approach profile provided the greatest noise reductions on the flight path centerline and for the measurement areas farther uprange. Slightly less than 6 SELdB noise reduction was measured when averaged over all the centerline microphones while nearly 9 SELdB noise reduction was measured when averaged over the centerline microphones located between 4,200 and $9,000 \mathrm{ft}(1,280$ and $2,743 \mathrm{~m}$ ) uprange. Greater than $10 \mathrm{SELdB}$ noise reduction was measured on centerline for a small area between 6,300 and $8,800 \mathrm{ft}(1,920$ and $2,682 \mathrm{~m})$ uprange. However, noise increases were measured between 1,000 and $3,000 \mathrm{ft}(304$ and $914 \mathrm{~m}$ ) uprange and up to $1,000 \mathrm{ft}(304 \mathrm{~m})$ to either sideline, with some very small pockets showing as much as a 
4 to 6 SELdB increase. Several other 3 deg to 9 deg approach profiles were tested during the Phase 3 test. Some of these profiles provided nearly as much noise reduction as the selected profile, while others provided significantly less noise reduction. It is the author's opinion that there is no one single approach profile that will provide the appropriate noise abatement characteristics to fit all possible landing sites. Rather, the approach profile will have to be tailored to each type of landing site. For instance, if the landing site is located on the top of a building in the center of a city, it might be appropriate to use a $3 \mathrm{deg}$ approach profile since it provides the most uniform noise abatement over the entire noise footprint. However, a $3 \mathrm{deg}$ to $9 \mathrm{deg}$ approach profile may be more appropriate for a landing site located at an airport or an industrial area that is surrounded by residential neighborhoods. If a landing point can be provided that is at least 2,000 to $3,000 \mathrm{ft}(610$ to $914 \mathrm{~m})$ beyond the residential neighborhoods, then a $3 \mathrm{deg}$ to $9 \mathrm{deg}$ approach profile would again provide the greatest noise reductions in those surrounding neighborhoods.

\section{CONCLUDING REMARKS}

Tiltrotor aircraft, with their unique capability to fly at relatively high cruise speeds like an airplane while maintaining the ability to take off and land vertically, provide a potential alternate means of transportation that could link major cities and alleviate some of the demand on airport runway usage. However, noise generated by the large tiltrotor aircraft is a potential barrier issue for civil market penetration. To address the issue of noise reduction, NASA initiated an effort with the goal of reducing the overall tilt-rotor approach noise within a 40 -acre ( 16 ha) vertiport by $12 \mathrm{~dB}$ relative to current (1995) technology. The goal is to obtain half the noise reduction through design and half through operations. A series of three $\mathrm{XV}-15$ acoustic flight tests have been conducted by a NASA/Army/Bell Helicopter team to evaluate the noise reduction potential for tiltrotor aircraft during terminal area operations by altering the nacelle angle/airspeed/altitude schedule.

During Phase 1 testing, acoustic measurements were obtained using a linear microphone array to measure the effective ground-plane noise contours for steady state flight operations. Results indicated that the takeoff and level flyover conditions had only a secondary effect on the total noise of tiltrotor operations, impacting land areas which are an order of magnitude less than those impacted during approach conditions. In addition, the effective ground-plane noise contours were converted to fixed radius lower hemispherical noise contours that were used as input to the RNM, which was then used to predict noise footprints for complex, multisegmented decelerating approaches.
The effective ground-plane noise contours from the Phase 1 test, along with the RNM predictions, were used to develop candidate low noise ILS-type approach profiles for Phase 2 testing. Handling qualities considerations also played an important role in the design of the noise abatement approach profiles. An advanced flight guidance system, which was linked to the DGPS tracking system, was utilized to perform these complex approach profiles with precision. During Phase 2 testing a large area microphones array was used to directly measure the ground noise footprints. Results indicated significant noise abatement potential by varying the approach profile parameters. In general, noise levels decreased with decreasing approach angles. The $3 \mathrm{deg}$ to 9 deg approach profile provided the greatest noise abatement at the far uprange distances, probably because the aircraft was on the quieter 3 deg glideslope, but about $300 \mathrm{ft}(91 \mathrm{~m})$ higher in altitude than the $3 \mathrm{deg}$ approach, due to the steeper $9 \mathrm{deg}$ segment during the final portion of the approach. The noise reductions measured reflected lower BVI noise generation resulting from more favorable nacelle angle/airspeed/altitude schedules. The data strongly suggested approaching at nacelle angles no higher than $60 \mathrm{deg}$ and maintaining these low nacelle angles for as long as possible.

The approach profiles from the Phase 2 test that provided the greatest noise reduction were further optimized and fully coupled with handling qualities considerations for testing during the Phase 3 test. In addition, the RNM was linked to an optimizer to develop additional approach profiles. All of the approach profiles were designed to be IFR approaches with the goal of achieving a handling qualities rating of three or better, which is sufficient for commercial passenger operations. The purpose of the final Phase 3 test was to demonstrate an integrated system approach to optimize the noise abatement for low noise approaches while fully coupling handling qualities with noise reduction, and to quantify the noise reductions provided by these approach profiles. The use of the $75 \mathrm{deg}$ flap setting was found to greatly improve the XV-15 handling quality characteristics during the steep, low-powered descent conditions that occurred during many of the approach profiles. Compared to the $6 \mathrm{deg}$ baseline approach profile, the $3 \mathrm{deg}$ approach profile provided a relatively uniform 4 to 6 SELdB noise reduction over much of the measurement area. The $3 \mathrm{deg}$ to 9 deg approach profile provided the greatest noise reductions on the flight path centerline and for the measurement areas farther uprange. Nearly 6 SELdB noise reduction was measured when averaged over all the centerline microphones (between 1,000 and $9,000 \mathrm{ft}$ [304 and $2,743 \mathrm{~m}$ ] uprange) while almost 9 SELdB noise reduction was measured when averaged over the centerline microphones located between 4,200 and $9,000 \mathrm{ft}(1,280$ and $2,743 \mathrm{~m})$ uprange. Greater than 10 SELdB noise reduction was measured on centerline 
for a small area between 6,300 and $8,800 \mathrm{ft}(1,920$ and 2,682 $\mathrm{m})$ uprange. More than 6 SELdB noise reduction was measured for much of the measurement area beyond 5,000 ft $(1,524 \mathrm{~m})$ uprange of the landing point. As a summary of the entire test series, this noise reduction and the associated flight procedure modifications are illustrated in Fig. 20.

The results of these tests indicate that there is no one single approach profile that is best for all landing sites. Rather, the approach profile should be tailored to the type of landing site. For instance, if the landing site is located on the top of a building in the center of a city, it might be appropriate to use a $3 \mathrm{deg}$ approach profile since it provides the most uniform noise abatement over the entire noise footprint. However, if the landing point has a 2,000 to $3,000 \mathrm{ft}$ (610 to 914 $m$ ) buffer zone surrounded by a noise-sensitive area, then a 3 deg to $9 \mathrm{deg}$ approach profile may be more appropriate, since it provides the greatest noise reductions beyond the buffer zone even while generating increased levels within the non-noise-sensitive buffer area.

During the latter two test phases, the profiles were flown as IFR approaches using the newly developed flight director. This allowed much more repeatable, precise profiles, but ones which were necessarily limited by the pilot's IFR workload. To allow enough time for the pilot to assimilate the flight director's visual cues and translate them into control inputs, a time delay, or buffer, of approximately 5 seconds had to be allowed for after each pilot instruction. This buffer produces elongated approaches compared to VFR approaches, where the aircraft can remain in the relatively quiet low-nacelle flight regime until very near the landing point. In the next few years, as these advanced DGPS based guidance systems are directly coupled to the aircraft control systems (thus reducing the pilot workload), precise, repeatable approaches will be possible in a shorter time/distance interval, as illustrated in Fig. 21. This will allow approaches that tend more toward the shorter VFR-type approaches. Civil tiltrotor operations will make use of the information derived from both VFR- and IFR-type acoustic testing to combine handling qualities and acoustic constraints in a highly efficient manner, thus allowing the noise reduction potential of the tiltrotor to be applied in precise, repeatable approaches to the public benefit.

\section{RECOMMENDATIONS}

Since the conclusion of this test series in 1999, the XV-15 has been fitted with the capability of performing automated approaches. This capability, while still in the developmental stage, now allows the direct control coupling discussed above. It is now possible to program a noise abatement approach into the $\mathrm{XV}-15$ flight control computer and demonstrate the acoustic benefits and reduced pilot workload which will characterize future tiltrotor operations. For this reason, one more $\mathrm{XV}-15$ acoustic test is needed. NASA is considering such a test, which would necessarily be conducted within the next calender year, since the XV-15 is nearing the end of its service life and will not likely be available after early 2002 .

FLIGHT PROCEDURE MODIFICATIONS REDUCE NOISE UP TO $10 \mathrm{~dB}$ Automated Flight Controls will allow these procedures to be flown consistently

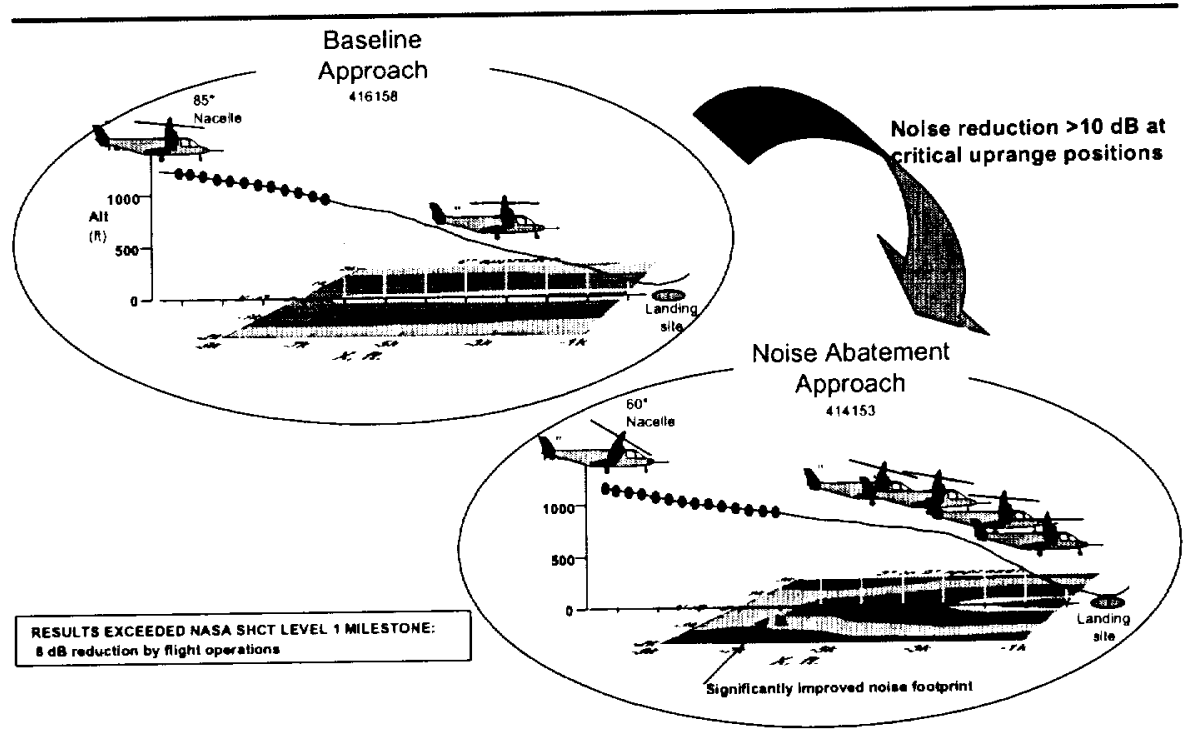

Fig. 20. Illustration of noise reduction due to flight procedure modification. 
With a focus on tiltrotor operations at airports, the test would include short takeoff or landing (STOL) operations and transient maneuvers as well as the automated approach operations. This one final XV-15 test would take advantage of this premier testbed aircraft in its most advanced configuration, providing acoustic data most representative of the lownoise potential of future tiltrotors.

\section{ACKNOWLEDGMENTS}

The authors would like to recognize the efforts of all of the personnel involved with the test program from Bell Helicopter Textron, Inc., NASA Ames and Langley Research Centers, the U. S. Army, and the associated contractors affiliated with these organizations. Without the extreme dedication of all of the people involved with the test program, the test would not have been a success. However, a few individuals and groups deserve special recognition for their efforts. These included Bell personnel Bill Martin for his work with the XV-15, Mark Stoufflet for his work developing and supporting the excellent real-time field displays of the tracking data, and Kelly Spivey for quickly processing all the $\mathrm{XV}-15$ onboard data. The field measurement team from Wyle Labs deserves special accolades for always having the acoustic measurement systems ready for testing and for keeping the weather balloon aloft on demand. Obviously, this test could not have been successful without the diligent efforts of the pilots, Roy Hopkins, John Ball, and Ron Erhart of Bell and Rick Simmons of NASA Ames. Finally, Charles Smith of Lockheed Martin Engineering and Sciences Co. deserves an enormous amount of credit for processing all of the acoustic data acquired during this test program while onsite, as well as assimilating all of the different types of data into one comprehensive data set. This paper would have been impossible without his efforts.

\section{REFERENCES}

1. Huston, R.J., Golub, R.A., and Yu, J.C., "Noise Considerations for Tiltrotor," AIAA Paper No. 89-2359, 1989.

2. George, A.R., Smith, C.A., Maisel, M.D., and Brieger, J.T., "Tilt Rotor Aircraft Aeroacoustics," American Helicopter Society 45th Annual Forum, Boston, MA, May 1989.

3. Marcolini, M.A., Burley, C.L., Conner, D.A., and Acree, Jr., C.W., "Overview of Noise Reduction Technology in the NASA Short Haul (Civil Tiltrotor) Program," SAE Technical Paper \# 962273, SAE International Powered Lift Conference, Jupiter, FL, November 1996.

4. "Fly Neighborly Pocket Guide," Helicopter Association International, 1993.

5. Mueller, A.W., Conner, D.A., Rutledge, C.K., and Wilson, M.R., "Full Scale Flight Acoustic Results for

\section{USE OF EARLY FLIGHT DIRECTOR ALLOWED PRECISION APPROACHES, BUT REDUCED OPTIONS FOR TERMINAL AREA NOISE REDUCTION}

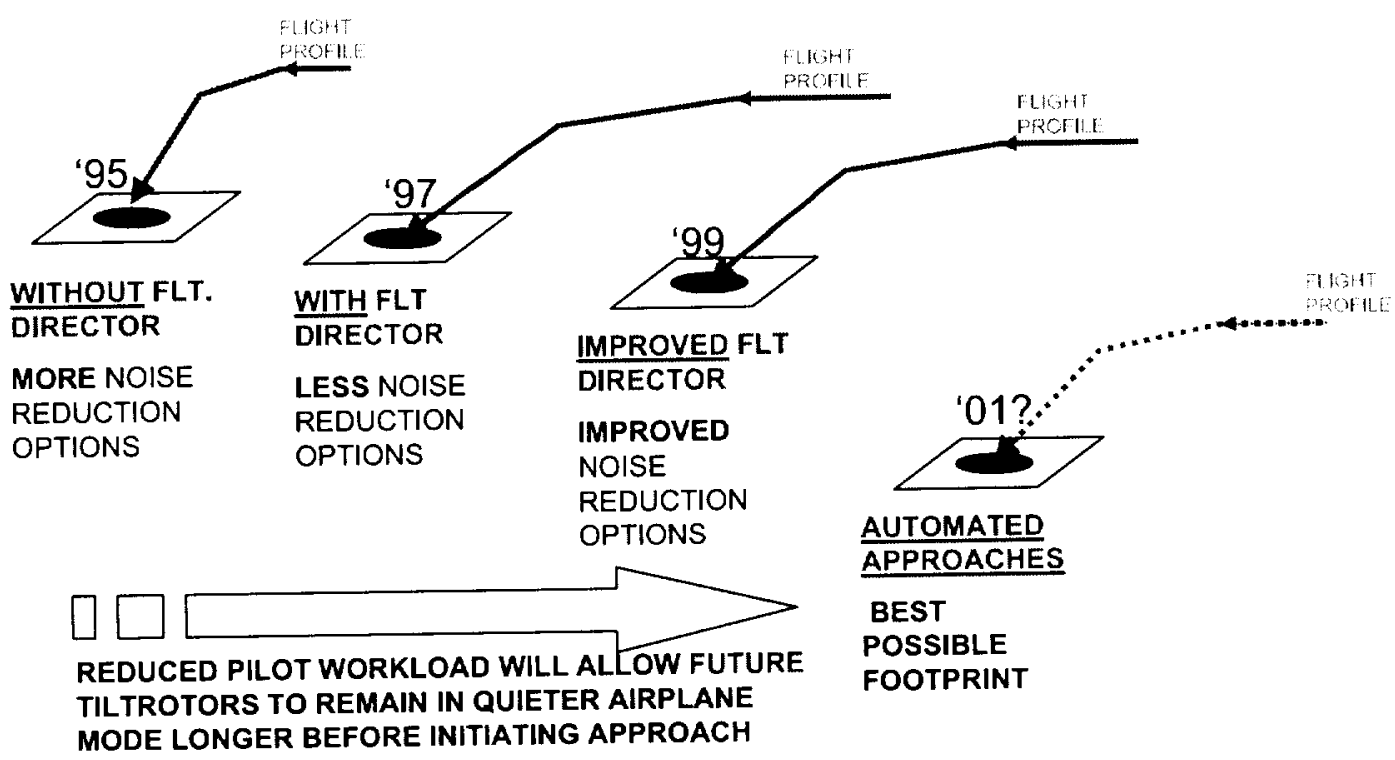

Fig. 21. Evolution of flight director and its effects onflight profile and noise abatement. 
the UH-60A Airloads Aircraft," American Helicopter Society Vertical Lift Aircraft Design Conference, San Francisco, CA, January 1995.

6. Wilson, M.R., Mueller, A.W., and Rutledge, C.K., "A New Technique for Estimating Ground Footprint Acoustics for Rotorcraft Using Measured Sound Fields," American Helicopter Society Vertical Lift Aircraft Design Conference, San Francisco, CA, January 1995.

7. Hindson, W.S., and Chen, R.T.N., "Flight Tests of Noise Abatement Approaches for Rotorcraft Using Differential GPS Guidance," American Helicopter Society 51 st Annual Forum, Ft. Worth, TX, May 1995.

8. Chen, R.T.N., Hindson, W.S., and Mueller, A.W., "Acoustic Flight Tests of Rotorcraft Noise-Abatement Approaches Using Local Differential GPS Guidance," American Helicopter Society Specialists Conference on Rotorcraft Aeromechanical Technologies, Fairfield County, CT, October 1995.

9. Jacobs, E.W., O'Connell, J.M., Conner, D.A., Rutledge, C.K., Wilson, M.R., Shigemoto, F., Chen, R.T.N., and Fleming, G.G., "Acoustic Flight Testing of a Boeing MD Explorer and a Sikorsky S-76B Using a Large Area Microphone Array," American Helicopter Society Technical Specialists Meeting for Rotorcraft Acoustics and Aerodynamics, Williamsburg, VA, October 1997.

10. JanakiRam, R.D., O'Connell, J.M., Fredrickson, D.E., Conner, D.A., and Rutledge, C.K., "Development and Demonstration of Noise Abatement Approach Flight Operations for a Light Twin-Engine Helicopter - MD Explorer," American Helicopter Society Technical Specialists Meeting for Rotorcraft Acoustics and Aerodynamics, Williamsburg, VA, October 1997.

11. Jacobs, E.W., Prillwitz, R.D., Chen, R.T.N., Hindson, W.S., and Santa Maria, O.L., "The Development and Flight Test Demonstration of Noise Abatement Approach Procedures for the Sikorsky S-76," American Helicopter Society Technical Specialists Meeting for Rotorcraft Acoustics and Aerodynamics, Williamsburg, VA, October 1997.

12. Lee, A., and Mosher, M., "An Acoustical Study of the XV-15 Tilt Rotor Research Aircraft," AIAA Paper No. 79-0612, 1979.

13. Conner, D.A., and Wellman, J.B., "Hover Acoustic Characteristics of the XV-15 with Advanced Technology Blades," AIAA Journal of Aircraft, Volume 31, Number 4, July-August 1994.

14. Brieger, J.T., Maisel, M.D., and Gerdes, R., "External Noise Evaluation of the XV-15 Tilt Rotor Aircraft,"
AHS National Technical Specialists' Meeting on Aerodynamics and Aeroacoustics, Arlington, TX, February 1987.

15. Edwards, B.D., "XV-15 Tiltrotor Aircraft Noise Characteristics," American Helicopter Society 46th Annual Forum, Washington, DC, May 1990.

16. Conner, D.A., Marcolini, M.A., Edwards, B.D., and Brieger, J.T., "XV-15 Tiltrotor Low Noise Terminal Area Operations," American Helicopter Society 53rd Annual Forum, Virginia Beach, VA, April-May 1997.

17. Conner, D.A., Marcolini, M.A., Decker, W.A., Cline, J.H., Edwards, B.D., Nicks, C.O., and Klein, P.D., "XV-15 Tiltrotor Low Noise Approach Operations," American Helicopter Society 55th Annual Forum, Montreal, Quebec, Canada, May 1999.

18. Lucas, M.J. and Marcolini, M.A., "Rotorcraft Noise Model," American Helicopter Society Technical Specialists' Meeting for Rotorcraft Acoustics and Aerodynamics, Williamsburg, VA, October 1997.

19. Conner, D. A., Edwards, B. D., Decker, W. A., Marcolini, M. A., and Klein, P. D., "NASA/Army/Bell XV15 Tiltrotor Low Noise Terminal Area Operations Flight Research Program," AIAA-2000-1923, June 2000.

20. "Tilt Rotor Research Aircraft Familiarization Document," NASA TMX-62407, Jan. 1975.

21. Klein, P.D., and Nicks, C.O., "Flight Director and Approach Profile Development for Civil Tiltrotor Terminal Area Operations," American Helicopter Society 54th Annual Forum, Washington, DC, May 1998.

22. Decker, W. A, "Piloted Simulator Investigations of a Civil Tilt-Rotor Aircraft on Steep Instrument Approaches," American Helicopter Society 48th Annual Forum, Washington, DC, June 1992.

23. Gray, D., Wright, K., and Rowland, W., "A FieldDeployable Digital Acoustic Measurement System," Technology 2000 (Proceedings published as NASA CP 3109, Vol. 2), Washington, DC, November 1990.

24. Padula, S.L., Korte, J.J., Dunn, H.J., and Salas, A.O., "Multidisciplinary Optimization Branch Experience Using iSIGHT Software," NASA TM-1999-209714, November 1999.

25. Yoshikami, S., "Flight Operations Noise Tests of Eight Helicopters," FAA-EE-85-7, Aug. 1985.

26. Gopalan, G., Schmitz, F.H., and Sim, B.W.-C., "Flight Path Management and Control Methodology to Reduce Helicopter Blade-Vortex Interaction (BVI) Noise," American Helicopter Society Vertical Lift Aircraft Design Conference, San Francisco, CA, January 2000. 